San Jose State University

SJSU ScholarWorks

Master's Theses

Master's Theses and Graduate Research

Fall 2020

\title{
Fire Weather Associated with the 2019 Northern California Public Safety Power Shutoff Events
}

Scott Purdy

San Jose State University

Follow this and additional works at: https://scholarworks.sjsu.edu/etd_theses

\section{Recommended Citation}

Purdy, Scott, "Fire Weather Associated with the 2019 Northern California Public Safety Power Shutoff Events" (2020). Master's Theses. 5159.

DOI: https://doi.org/10.31979/etd.w9ez-52xy

https://scholarworks.sjsu.edu/etd_theses/5159

This Thesis is brought to you for free and open access by the Master's Theses and Graduate Research at SJSU ScholarWorks. It has been accepted for inclusion in Master's Theses by an authorized administrator of SJSU ScholarWorks. For more information, please contact scholarworks@sjsu.edu. 
FIRE WEATHER ASSOCIATED WITH THE 2019 NORTHERN CALIFORNIA PUBLIC SAFETY POWER SHUTOFF EVENTS

\author{
A Thesis \\ Presented to \\ The Faculty of the department of Meteorology and Climate Science \\ San José State University \\ In Partial Fulfillment \\ of the Requirements for the Degree \\ Master of Science \\ by \\ Scott Purdy \\ December 2020
}


(C) 2020

Scott Purdy

ALL RIGHTS RESERVED 
The Designated Thesis Committee Approves the Thesis Titled

FIRE WEATHER ASSOCIATED WITH THE 2019 NORTHERN CALIFORNIA PUBLIC SAFETY POWER SHUTOFF EVENTS

by

Scott Purdy

APPROVED FOR THE DEPARTMENT OF METEOROLOGY AND CLIMATE SCIENCE

SAN JOSÉ STATE UNIVERSITY

DECEMBER 2020

Dr. Craig B. Clements Department of Meteorology and Climate Science

Dr. Adam Kochanski Department of Meteorology and Climate Science

Dr. Patrick Brown Department of Meteorology and Climate Science 


\title{
ABSTRACT
}

FIRE WEATHER ASSOCIATED WITH THE 2019 NORTHERN CALIFORNIA PUBLIC SAFETY POWER SHUTOFF EVENTS

\author{
by Scott Purdy
}

Recent high impact wildfire events across California have piloted the implementation of grid de-energization by utilities across the state. The largest utility, Pacific Gas and Electric (PG\&E), deployed this tactic on seven separate occasions during 2019, four of which occurred in October. This recent ploy has been established in the wake of many deadly wildfires such as the 2018 Camp Fire as an ignition mitigation tactic. Conditions such as the state of the fuels, meteorological conditions, and the consequent fire danger were evaluated as the primary triggers for the October de-energizations. It was determined that the fuels were critically dry and conducive for large wildfires, and three of the four events measured meteorological conditions in excess of PG\&E's pre-defined thresholds. A primary forecast tool for PG\&E is the Weather Research and Forecasting (WRF) model, and this model was used for reanalysis simulations to expose the model's proficiencies and deficiencies. The need for a properly configured WRF was confirmed. Further, sub kilometer grid resolutions were not beneficial for windspeed forecasting. Ultimately, PSPS are necessary procedures for wildfire mitigation, but they are not a long-term solution. Utility companies must implement infrastructure hardening tactics. Meanwhile, improvements in forecasting PSPS conditions with WRF are necessary. 


\section{ACKNOWLEDGEMENTS}

I am forever gracious for the education and opportunities I have been given by SJSU's Department of Meteorology and Climate Science as well as the financial assistance from the Walker Fellowship. I would like to give a special thanks to my entire thesis committee for their time and assistance throughout this

process. In particular, I would like to thank my advisor Dr. Craig Clements for the countless intellectual conversations and reinforcing positivity. Additionally, thank you to Mike Voss for the essential forecaster insight that was provided along the way.

I would like to thank the team members of the Fire Weather Research Lab for making this graduate experience truly unique with countless adventures in the field. Of course, a huge thanks goes out to all the family that has supported me in so many different ways for the duration of this process.

Lastly, this research was made possible by NSF ICER-1664713; AGS1807774 , and PG\&E Contract No. C6909 funding. 


\section{TABLE OF CONTENTS}

List of Tables................................................................................. vii

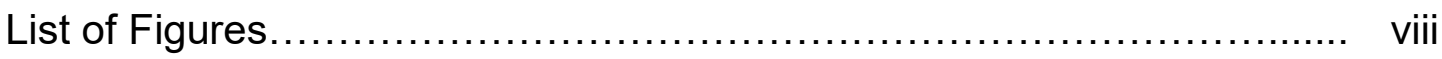

Chapter 1: Observational Assessment of Environmental and Meteorological Conditions During the Public Safety Power Shutoffs of October 2019.

1.1 Introduction

1.2 Data and Methods.

a) Gridded Meteorological Data................................................... 8

b) Surface and Sounding Data.................................................. 9

c) Mobile Deployment Instrumentation......................................... 9

d) Fuel Moisture Content Data................................................. 10

1.3 State of the Fuels.................................................................. 11

1.4 Wind Event Descriptions................................................... 13

a) Wind Event 1.............................................................. 13

b) Wind Event 2 ..................................................................... 21

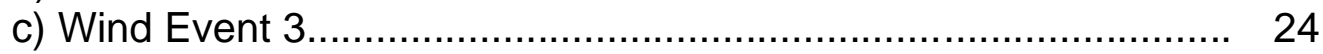

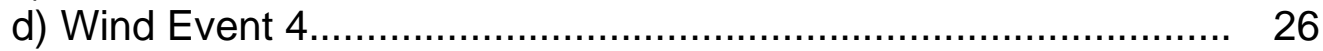

e) Wind Event 5............................................................. 28

1.5 Weather and Fuels Cumulative Effect on Fire Danger.................. $\quad 30$

1.6 Discussion and Summary....................................................... $\quad 34$

Chapter 2: Numerical Simulations of the October 2019 PSPS events...... 39

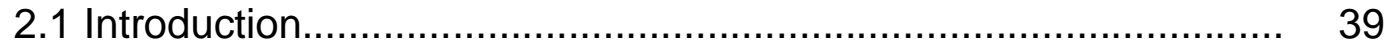

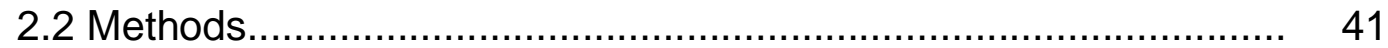

2.3 Model Performance............................................................... 46

a) Model Configuration......................................................... 46

b) Surface Network Performance........................................... 47

c) Horizontal Resolution Optimization..................................... $\quad 50$

d) Gray Zone Exploration..................................................... 50

2.4 Mountain Wave Analysis....................................................... 51

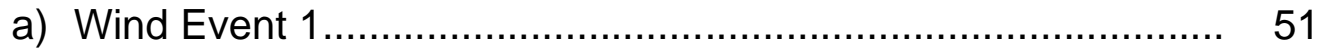

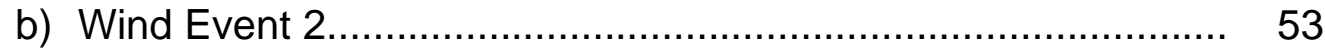

c) Wind Event 3................................................................. 56

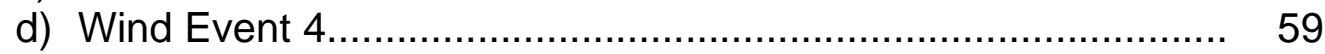

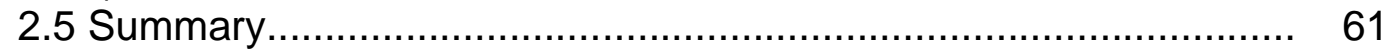

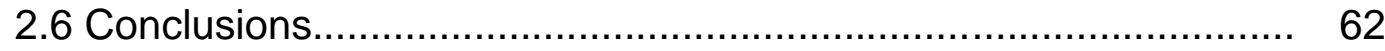

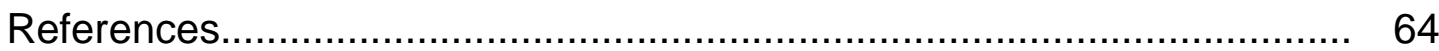




\section{LIST OF TABLES}

Table 1. A comprehensive list of each PSPS performed by PG\&E and the estimate of affected customers that were associated with each de-energization............................... 5

Table 2. Maximum pressure gradients $(\triangle \mathrm{hPa})$ from San Francisco to Winnemucca (SFO-WMC) and from Redding to Sacramento (RDD-SAC) ............................................ 6

Table 3. List of surface weather stations used for WRF calibration. 45

Table 4. Summary of WRF parameterization options..................... 46

Table 5. Details are listed for each simulations' start and end times 


\section{LIST OF FIGURES}

Figure 1. (a) Surface weather stations are overlaid on terrain height (meters)

Figure 2. Live fuel moisture content observations of chamise for the Wine Country (a), Sierra (b), and Bay Area (c) regions

Figure 3. Surface observations of sustained windspeed (black line), gusts (dotted black line), wind direction (teal plus symbols), and $\mathrm{RH}$ (red line) for WE1 (27/00 through 28/12) and WE4 (29/12 through 31/00).

Figure 4. Synoptic overview utilizing the Global Forecast System (GFS) $0.5^{\circ}$ analysis product.

Figure 5. NWS soundings from Reno Nevada (a,b,c,d,e) and Oakland California $(f, g, h, I, j)$.....

Figure 6. Data furnished from the CSU-Maps deployment 27 October 2019.

Figure 7. As in Figure 3, but focused on WE2 ............................ 2

Figure 8. As in Figure 3, but focused on WE3............................ 25

Figure 9. As in Figure 3, but focused on WE5............................ 29

Figure 10. The yellow shaded regions depict PSPS outages........... 32

Figure 11. The maximum LFP $P_{w}$ for each site during each wind event and grouped by region

Figure 12. Domains for WRF simulation with topography shaded in meters.

Figure 13. Domain 4 overview with a few key locations marked in red.

Figure 14. WRF's surface wind speed $\left(\mathrm{m} \mathrm{s}^{-1}\right)$ forecast performance for all networks. 
Figure 15. Cross section of temperature from Figure 13 during WE1 simulation.....

Figure 16. Cross section of streamwise windspeed from Figure 13 during WE1 simulation................................................ 53

Figure 17. Same as Figure 15, but for WE2 .................................. 55

Figure 18. Same as Figure 16, but for WE2 ................................ 56

Figure 19. Same as Figure 15, but for WE3 .................................. 58

Figure 20. Same as Figure 16, but for WE3 ................................. 59

Figure 21. Same as Figure 15, but for WE4 ................................ 60

Figure 22. Same as Figure 16, but for WE4 ................................. 61 


\section{Chapter 1 \\ Fire Weather Associated with the 2019 Northern California Public Safety Power Shutoff Events}

\subsection{Introduction}

Wildfires in California have taken more than 100 lives, both firefighters and civilians, in recent years. To date, California's most destructive and second most destructive wildfires in history were the Camp Fire of 2018 and the Tubbs Fire of 2017, respectively [1]. An investigation led by Cal Fire determined that Pacific Gas and Electric (PG\&E) was responsible for the ignition of the Camp Fire [2]. This event, among many others, sparked extensive modifications to the operational structure of investor owned utilities (IOU).

In response to events such as the Camp Fire, IOUs across California have implemented a newer procedure called public safety power shutoffs (PSPS). A PSPS involves the active de-energization for targeted portions of an energy grid that are implemented when environmental conditions including but not limited to, strong and gusty winds, low relative humidity $(\mathrm{RH})$, and dry fuels are exhibited [3]. Thresholds were defined vaguely where any of the following can warrant grid de-energization including sustained winds above $11.18 \mathrm{~m} \mathrm{~s}^{-1}$ (25mph), gusts in excess of $20.12 \mathrm{~m} \mathrm{~s}^{-1}(45 \mathrm{mph}), \mathrm{RH}$ generally $20 \%$ and below, and dry fuel conditions. PG\&E executed their first PSPS in October 2018 which was followed by seven more events in 2019 according to the California Public Utilities Commission (CPUC) [4]. Of the seven PSPS events initiated by PG\&E in 2019, four occurred in the month of October. The controversy over this new procedure 
sparked an investigation by the CPUC [5]. A brief meteorological assessment of the events under investigation, revealed that the majority of these PSPS events occurred during periods of offshore flow (not shown).

Offshore flow in California has been known to yield downslope windstorms, and subsequently the leeward slopes of significant topographic features experience the most vulnerability. Previous studies have linked downslope windstorms to deadly and destructive wildfires [6-9]. Downslope windstorms are often referred to as a foehn wind and are usually attributed to the amplification and deflection of mountain waves $[10,11]$. Criteria necessary for this amplification and deflection of mountain waves includes strong winds $7-15 \mathrm{~m} \mathrm{~s}^{-1}$, flowing within 30 degrees of perpendicular to the ridge line, and an inversion or layer of strong stability, located near or above crest height upstream of the mountain $[7,12]$. Mountain height and slope are regionally dependent factors that can contribute to the wavelength and amplitude of the mountain wave and subsequent downslope winds [11]. Locally named downslope windstorms in northern California include the North Winds in the northern Sierra Nevada [7] and the Diablo Winds in the Coast Ranges of the San Francisco Bay Area [9]. Wind and atmospheric moisture have been shown to directly affect a fire's rate of spread which is why the dry and windy conditions associated with downslope windstorms pose a serious threat if an ignition were to occur [13].

Given an ignition, dry and windy conditions need only one additional variable to promote large wildfires and that is dry fuels. Vegetation, or fuels, are a major 
factor associated with de-energization decisions that must also be considered. Fuels are categorized as live or dead, and the fuel moisture content (FMC) is the key component of interest. FMC refers to the water content of living or dead vegetation, calculated as a percentage of dry mass [14]. Dead vegetation is categorized as $1,10,100$, and 1000-hour fuels which is representative of the time lag it takes the dead fuel to reach $63 \%$ moisture equilibrium with the ambient atmospheric conditions [15].

Live FMC in California is typically analyzed using specific plant species, and often Chamise (Adenostoma fasciculatum) is used as a general representation of the state of live FMC across California because it is common and can be found in southern California, the Coast Ranges of central California, and the lower Sierra Nevada Foothills [16]. Live FMC is often a focal point in the early season because it has the longest seasonal delay, and the early season patterns observed often set the stage for late season conditions. Generally, by midsummer, most dead fuels are sufficiently dry for large wildfire potential. In the late season, once dormancy for most live fuel is attained, the moisture remains relatively low until growth resumes in the spring [17]. Climatologically, precipitation returns to much of Northern California in mid to late October. Consequently, dead fuels become a focal point for the assessment of wildfire potential owing to their response times which are better suited to assess more abrupt impacts of individual precipitation events. The complex interactions 
between fuel-based impacts and meteorological conditions are quantified by the National Fire Danger Rating System (NFDRS) [18].

To the best of our knowledge, no observational quantification of the environmental conditions during PSPS events have been performed. The goal of this study is to quantify key environmental factors such as FMC, atmospheric humidity, wind intensity, and geographic and temporal characteristics of wind patterns associated with these public safety power shutoffs. In addition to the analysis of direct surface weather conditions, synoptic analyses were made to better understand the meteorological environment associated with these events.

\subsection{Data and Methods}

This paper will focus on the events that occurred in October as it encompassed both the largest and smallest PSPS events regarding affected population counts, and more than half of the total events occurred in October (Table 1). These data were compiled from each of the Pro-Active DeEnergization Post Event Reports [19]. Our analysis first focused on the state of the fuels across northern California followed by analyses of atmospheric conditions during each wind event. Finally, the complex relationship between weather and fuels was quantified in terms of fire danger using NFDRS outputs. 
Table 1. A comprehensive list of each PSPS performed by PG\&E and the estimate of affected customers that was associated with each de-energization. The bolded dates are the events analyzed herein which have each been assigned an ordinal abbreviation based on intensity where WE1 represented the most intense event.

\begin{tabular}{lcc} 
PG\&E PSPS events & $\begin{array}{c}\text { Estimate of affected } \\
\text { customers }\end{array}$ & $\begin{array}{c}\text { Wind Event } \\
\text { Abbreviated Identifier }\end{array}$ \\
\hline June $8-9$ & $\sim 22,474$ & \\
September $23-26$ & $\sim 70,826$ & \\
\hline October $\mathbf{5}-\mathbf{6}$ & $\sim 11,609$ & WE5 \\
October $\mathbf{9}-\mathbf{1 2}$ & $\sim 735,440$ & WE2 \\
October $\mathbf{2 3}-\mathbf{2 5}$ & $\sim 178,800$ & WE3 \\
October $\mathbf{2 6}-$ November $\mathbf{1}$ & $\sim 967,700$ & WE1, WE4 \\
\hline November $20-21$ & $\sim 49,000$ & \\
\hline
\end{tabular}

The events were categorized ordinally and abbreviated where wind event 1 (WE1) was the most intense event and WE5 was the least intense event. Among the data analyzed herein, the most direct and descriptive relationship observed for event intensity was the pressure gradient from Redding (KRDD) to Sacramento (KSAC) and was subsequently used to ordinally categorize the events (Table 2). These sites are geographically situated in the Central Valley between the Sierra Nevada and the Coast Ranges with minimal elevation change between the two sites (Figure 1a). The pressure gradient between these two locations was representative of the synoptically driven North winds that channel through the Central Valley and ultimately impact the Wine Country and Bay Area regions. It should be noted that this method is aimed at quantifying the expected intensity with the assumption that there exists a direct relationship between surface pressure gradient and wind speed. The added effects of mesoscale features such as onset of downslope windstorms add further complexity and 
therefore may alter the observed intensity of each specific event. Data use for these analyses included gridded meteorological data, surface weather data, vertical wind profiles, and FMC data.

Table 2. Maximum pressure gradients $(\triangle \mathrm{hPa})$ from San Francisco to Winnemucca (SFO-WMC) and from Redding to Sacramento (RDD-SAC) were extracted from surface observations for each wind event. Surface station locations are shown in Figure 1. The events were ordinally abbreviated based on the intensity of the (RDD-SAC) gradient where WE1 represented the strongest gradient and WE5 represented the weakest gradient.

\begin{tabular}{|c|c|c|c|}
\hline Date & $\begin{array}{c}\text { SFO-WMC } \\
(\Delta \mathrm{hPa})\end{array}$ & $\begin{array}{c}\text { RDD-SAC } \\
(\Delta \mathrm{hPa})\end{array}$ & Ordinal Abbreviation \\
\hline $10 / 6 / 2019$ & -12.9 & 2 & WE5 \\
\hline $10 / 10 / 2019$ & -16 & 6.4 & WE2 \\
\hline $10 / 24 / 2019$ & -16.7 & 5.6 & WE3 \\
\hline $10 / 27 / 2019$ & -12 & 10.6 & WE1 \\
\hline $10 / 30 / 2019$ & -16.7 & 5 & WE4 \\
\hline
\end{tabular}



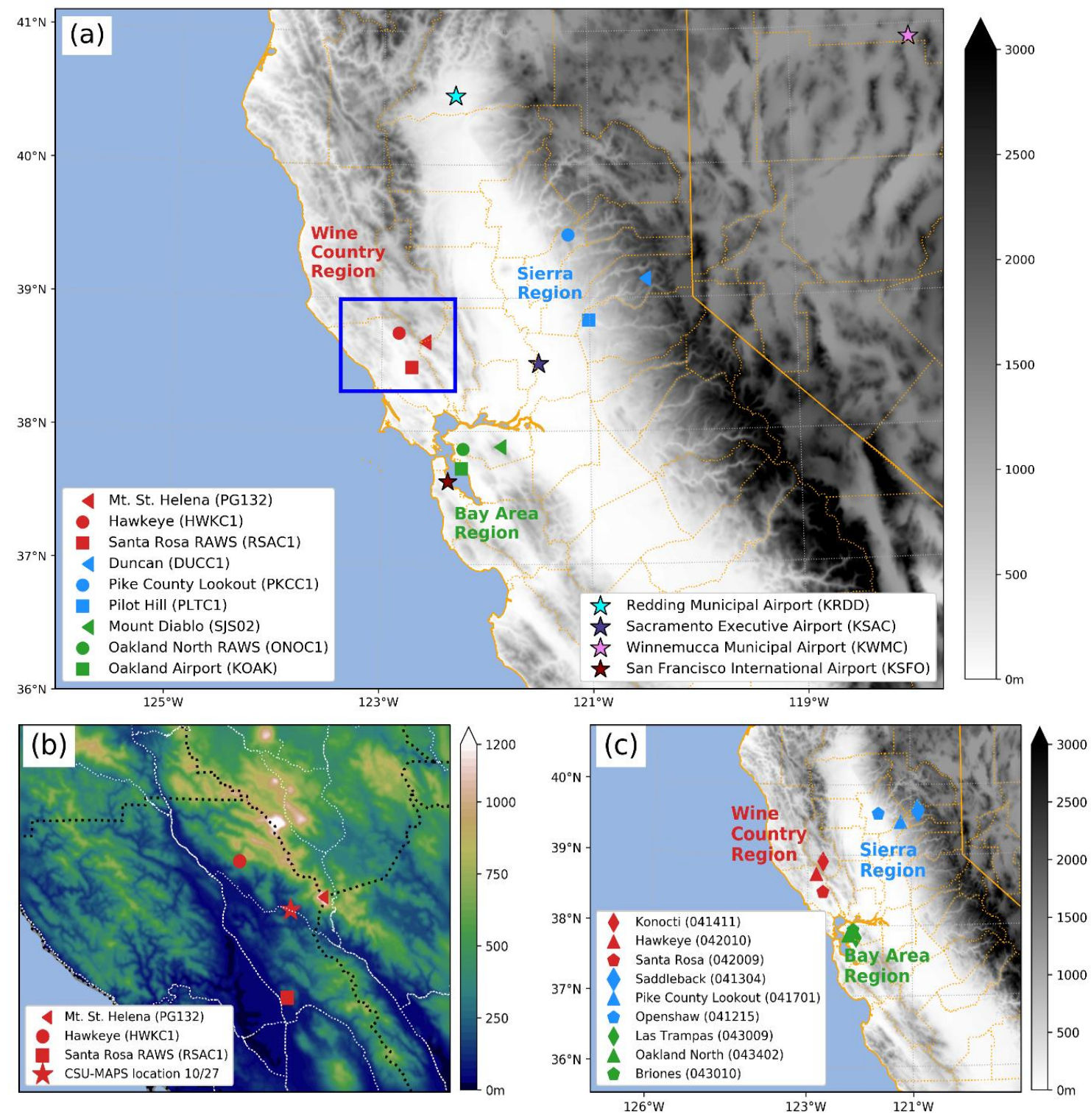

Figure 1. (a) Surface weather stations used in the meteorological analysis were overlaid on terrain height (meters). Stars are surface stations utilized for pressure gradient calculations and were not used for the regional analyses. All other symbols in red, green, and light blue denote the Wine Country, Bay Area, and Sierra Region, respectively. Triangles, circles, and squares denote high, mid, and low elevation sites for each respective region. (b) An inset from panel a, focused on the Wine Country region to orient lidar location. (c) As in panel a, but with stations that were used for the fire danger analysis. 


\section{a. Gridded Meteorological Data}

Data from the Global Forecast System (GFS) were used for the synoptic analyses. Specifically, the GFS $0.5^{\circ}$ analysis data were used to assess the 500 $\mathrm{hPa}$ wind and geopotential height, $850 \mathrm{hPa}$ cold air advection (CAA), and mean sea level pressure (MSLP) and 2-meter dewpoint temperatures coincident with the peak of each wind event. The peak of the wind event was defined by the maximum surface gust recorded and the time of that observation was approximated to the nearest GFS output. The synoptic analysis unveiled that five unique offshore flow events occurred during the four de-energizations of interest which was important for constructing the framework of the surface analysis. PG\&E's territory has three key regions of vulnerability during such an event. The three vulnerable, yet distinct, areas include the Wine Country, Bay Area, and Sierra regions which were each analyzed separately (Figure 1a). Additional meteorological data were used to assess precipitation events that may have occurred during the Autumn of 2019.

The National Weather Service (NWS) Advanced Hydrologic Prediction Service provided a gridded $4 \mathrm{~km}$ data set of the departure from normal precipitation [20]. Precipitation departures were calculated using the 30-year average from 1981-2010. The observational precipitation anomalies were used to aid in analyzing the state of the fuels. 


\section{b. Surface and Sounding Data}

Surface weather stations and atmospheric soundings were collected from MesoWest [21] and the University of Wyoming Sounding archive [22], respectively. Surface weather stations were selected to best represent a high, mid, and low elevation site on the lee side of topography in the Wine Country, Bay Area, and Sierra regions (Figure 1a). This was designed to comprehensively examine the winds within each region at different elevations of the complex terrain that commonly observe downslope windstorms.

Atmospheric soundings, for each event, were collected from upstream (downstream) in Reno, Nevada (Oakland, California) for analysis of the vertical profile. Many aspects of the vertical profiles were analyzed including evaluation for the presence of a stable layer which is critical for downslope development. Because of a lack of high temporal and spatial resolution vertical atmospheric profiles in the regions of interest, particularly during the onset of the wind events, mobile deployment of a Doppler lidar to the Wine Country region was employed to obtain high-resolution vertical wind profiles.

\section{c. Mobile Deployment Instrumentation}

To better observe the ambient wildfire environment mobile measurement assets such as Doppler lidar were used. The California State University Mobile Atmospheric Profiling System (CSU-MAPS) [23] was deployed to the Kincade fire which was burning during multiple PSPS events (24 October and 27 October). 
CSU-MAPS was equipped with a Halo Photonics scanning Doppler lidar and an automatic weather station. Vertical wind profiles were obtained from the lidar during the early morning hours of 27 October. Additionally, surface weather data including wind speed and $\mathrm{RH}$ were collected from a co-located surface weather station. The CSU-MAPS was positioned in Knights Valley near the base of the Mayacamas Mountains (Figure 1b). This position was advantageous for understanding the ambient atmosphere near the southern flank of the Kincade fire and was well situated for observations of the unfolding downslope windstorm [24]. These data are used to investigate the complex characteristics associated with the onset of the most severe Diablo Wind event of 2019.

\section{d. Fuel Moisture Content Data}

Observations of live FMC typically have sparse spatial and temporal coverage. These limitations constrained the analysis of live FMC to one site per region. Selected sites were required to have comprehensive historical data and continuous observations throughout 2019. Chamise was rendered the best fuel for assessment of regional live FMC differences due to its data availability and wide geographic prevalence.

As previously mentioned, dead fuels are an important focal point later in the fire season. NFDRS output was used for 100-hour fuels values which were chosen due to their longer response times to changing weather conditions. Three remote automatic weather station (RAWS) sites from each of the Wine Country region, Bay Area region, and Sierra region were used to derive fire 
danger metrics. The RAWS weather data were collected [25] and used in Fire Family Plus 5 to calculate the 100-hour FMC, Energy Release Component (ERC), Burning Index (BI), Spread Component (SC), Ignition Component (IC), and the Fosberg Fire Weather Index (FFWI) which are common outputs of NFDRS. A common fuel model was selected for all stations to maintain regional similarities, but all other station metadata remained default. Both fuel models B (California chaparral) and $\mathrm{G}$ (timber) were tested as fuel model controls and B was chosen due to increased variability between PSPS events.

\subsection{State of the Fuels}

Fuels dynamically respond to both precipitation and ambient atmospheric conditions [26]. A culmination of the atmospheric conditions on seasonal time scales ultimately determine the FMC at any given time. California summers are typically dry with significant precipitation resuming in the fall months [27]. Native plants such as chamise have adapted to survive in this seasonal drought, but stress related to moisture deficiencies are inevitable. One chamise sampling site per region was selected as a proxy for the state of the fuels in its respective region (Figure 2). The response chamise has to seasonal moisture deficits differs slightly among the three regions (Fig. 2a-c). On average, all three regions had a decreasing trend in live FMC by June, although above average for most of the summer caused by above average antecedent winter precipitation. This downward trend in FMC leveled off between September and October with a minimum average $\mathrm{FMC}$ roughly $60 \%$. Critical live FMC, the threshold above 
which large wildfires do not occur, was proposed at $79 \%$ [14]. The climatological average among all three regions descended below this critical threshold before 1 August and persisted through 15 November. Further, minimal change in FMC is observed in autumn owing to vegetation dormancy which inhibits significant changes in moisture until growth resumes in the spring [17].
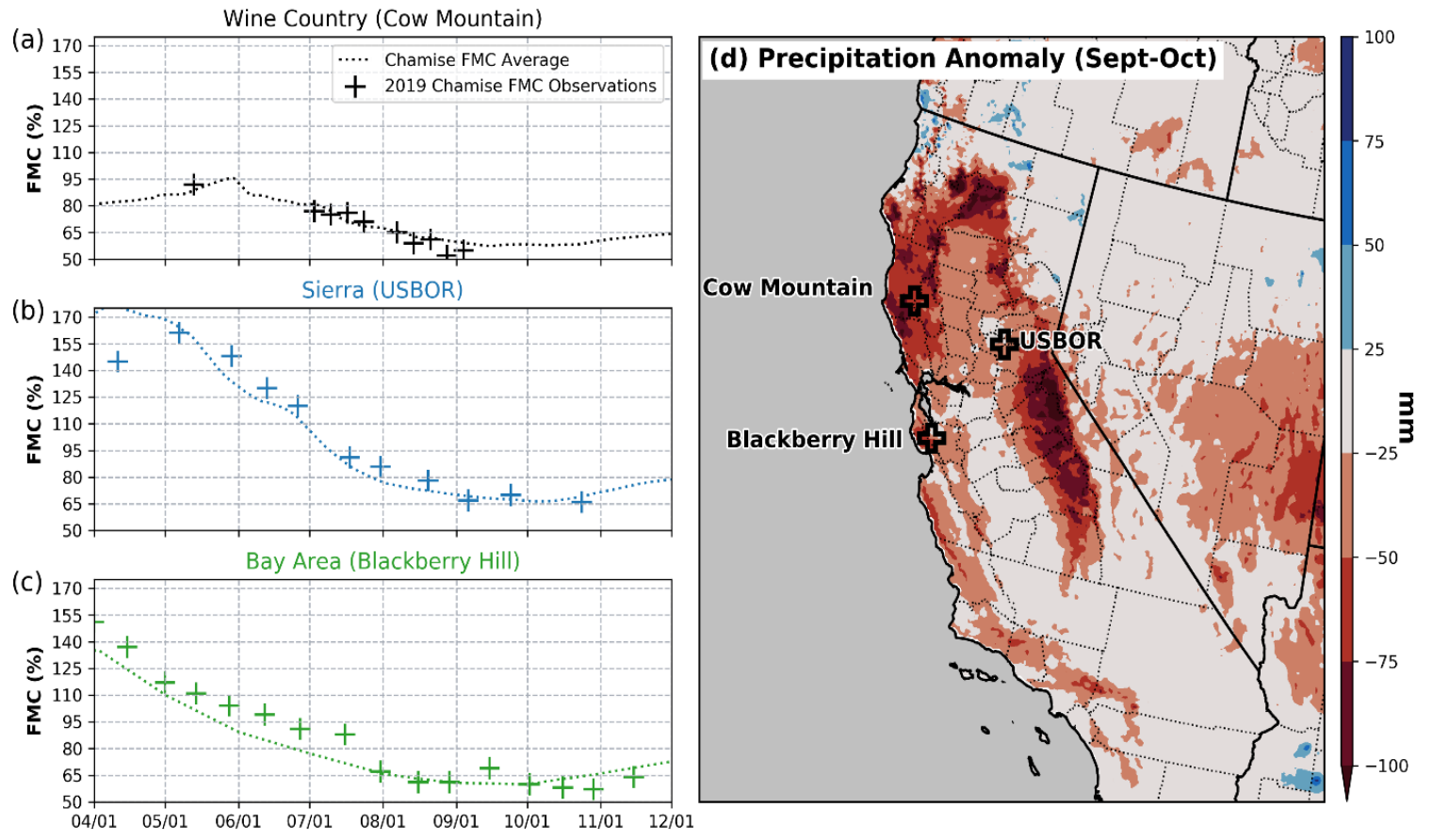

Figure 2. Live fuel moisture content observations of chamise for the Wine Country (a), Sierra (b), and Bay Area (c) regions. The plus symbols represent 2019 observations and dotted lines represent site specific climatological averages. Observed precipitation departure from normal for September and October 2019 supplied by the National Weather Service (NWS) Advanced Hydrologic Prediction Service with sites of live fuel moisture content overlaid (d).

Observations confirmed that 2019 followed the overall climatological trend in FMC with a few minor differences (Figure 2a,b,c). All regions observed average to slightly above average FMC for much of the 2019 season until September when FMC values fell below average. This was consistent with below average 
precipitation for the time of year (Figure 2d). Therefore, live fuels in October 2019 were prime for wildfire activity across all regions of interest. The dead fuels are also very important, but due to their shorter response times they will be analyzed later in the event inter-comparison.

\subsection{Wind Event Analysis}

\section{a. Wind event 1 (WE1)}

WE1 produced peak winds at approximately 1200 UTC 27 October 2019 with gusts in excess of $44.7 \mathrm{~m} \mathrm{~s}^{-1}(100 \mathrm{mph})$ at a ridgetop location near Pine Flat Road in the Wine Country region (not shown). The valley below observed wind gusts of roughly $30 \mathrm{~m} \mathrm{~s}^{-1}$ at the Santa Rosa RAWS and was associated with RH less than $10 \%$. Very similar characteristics were observed in both the Sierra and Bay Area regions except the intensity was less than the conditions observed in the Wine Country. Pine Flat Road consistently observed some of the strongest gusts throughout the events, although relative humidity was observed to be less consistent with often erroneous data indicating a problem with the station. Therefore, this site was excluded from the regional analyses.

During this event, the evolution of the surface conditions varied among the three regions but lasted approximately 30 hours at all three zones (Figure 3). The Sierra and Wine Country regions observed a two-phase evolution that was characterized by a decrease in wind intensity at roughly 0000 UTC on 28 October. This multi-phase evolution has been previously documented regarding Santa Ana wind events primarily attributed to diurnal effects [28]. The observed 
multi-phase evolution was associated with a decrease in wind intensity at approximately 0000 UTC with the likely primary mechanism being weakening gravity waves through destabilization of the lower levels and surface heating [29]. The multi-phase variations did not impact the atmospheric moisture content, only the wind intensity.
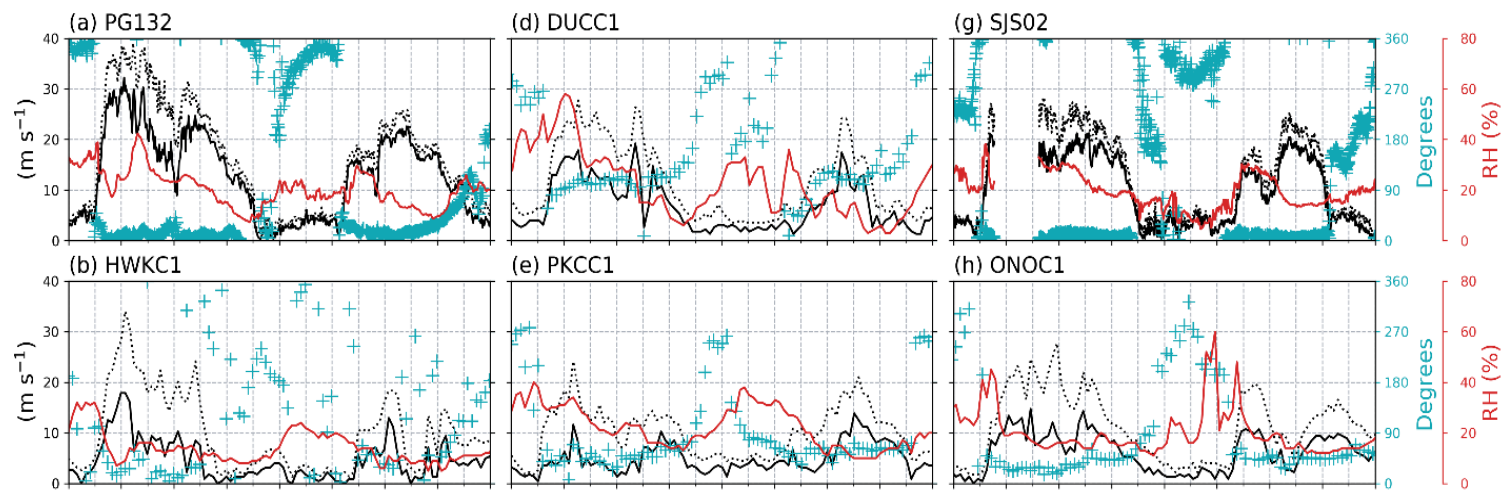

(h) ONOC1
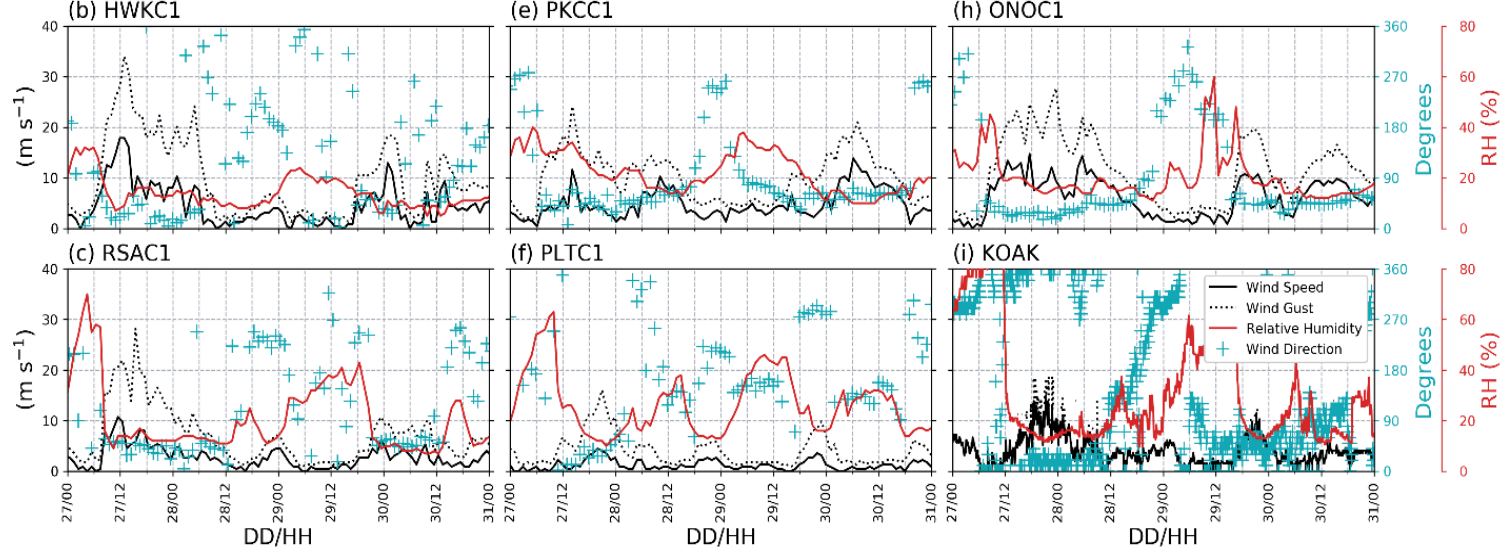

Figure 3. Surface observations of sustained windspeed (black line), gusts (dotted black line), wind direction (teal plus symbols), and RH (red line) for WE1 (27/00 through 28/12) and WE4 (29/12 through 31/00). Panels (a,b,c), (d,e,f), and $(\mathbf{g}, \mathbf{h}, \mathbf{i})$, were observed in the Wine Country, Sierra, and Bay Area regions, respectively. Panels $(\mathbf{a}, \mathbf{d}, \mathbf{g}),(\mathbf{b}, \mathbf{e}, \mathbf{h})$, and $(\mathbf{c}, \mathbf{f}, \mathbf{i})$ were observed at high, mid, and low elevations, respectively. Station identifiers are located above their respective data.

The synoptic forcing of WE1 was quite dominant at multiple levels of the atmosphere. A high amplitude shortwave trough at $500 \mathrm{hPa}$ had a strong positively tilted axis that was perpendicular to the California coast (Figure 4a). Wind speeds at this level associated with the trough exceeded $50 \mathrm{~m} \mathrm{~s}^{-1}$. This shortwave advected cold air into the Great Basin and northern California and was 
associated with strong low-level CAA of $10^{\circ} \mathrm{C}$ per six hours at $850 \mathrm{hPa}$ (Figure 4b). The surface pressure gradient was greatest along the western slopes of the Sierra Nevada and extended across northern California (Figure 4c). Associated with this strong surface pressure gradient were dewpoint temperatures approximately $-10^{\circ} \mathrm{C}$ across northern California. 

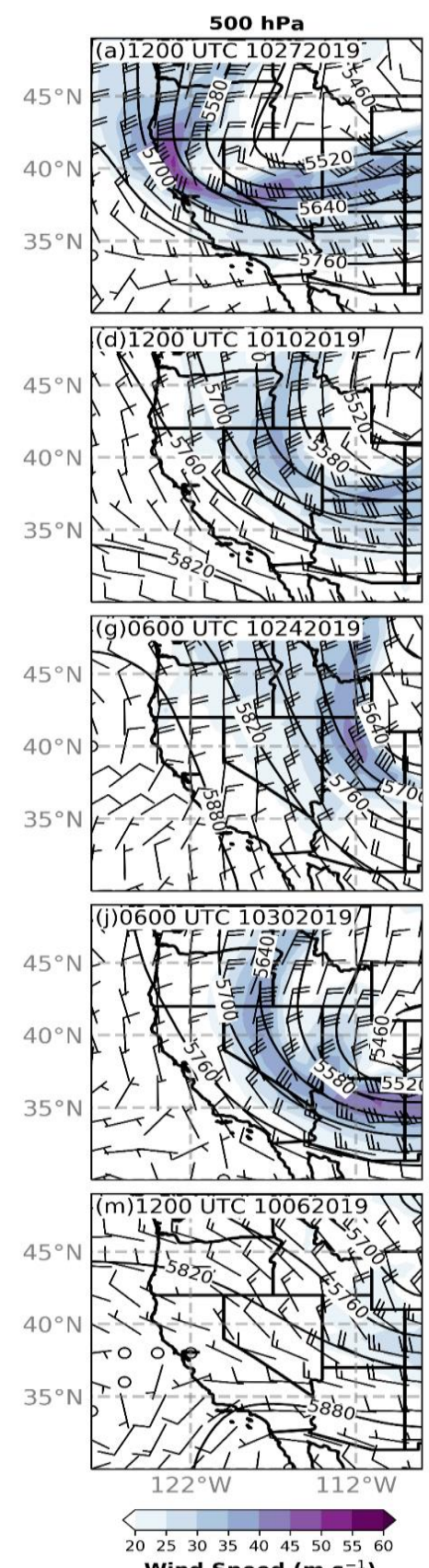

Wind Speed $\left(\mathrm{m} \mathrm{s}^{-1}\right)$
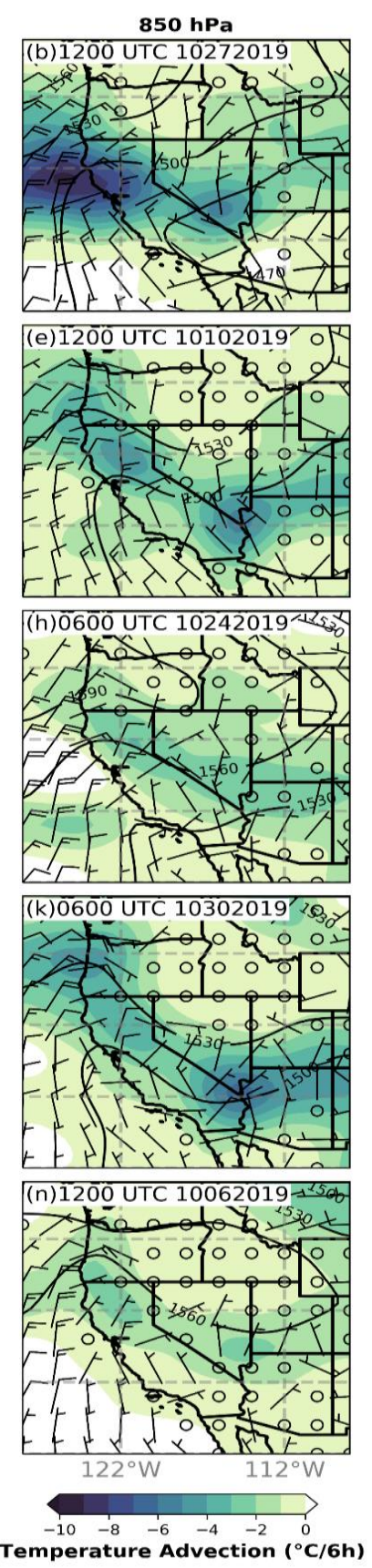
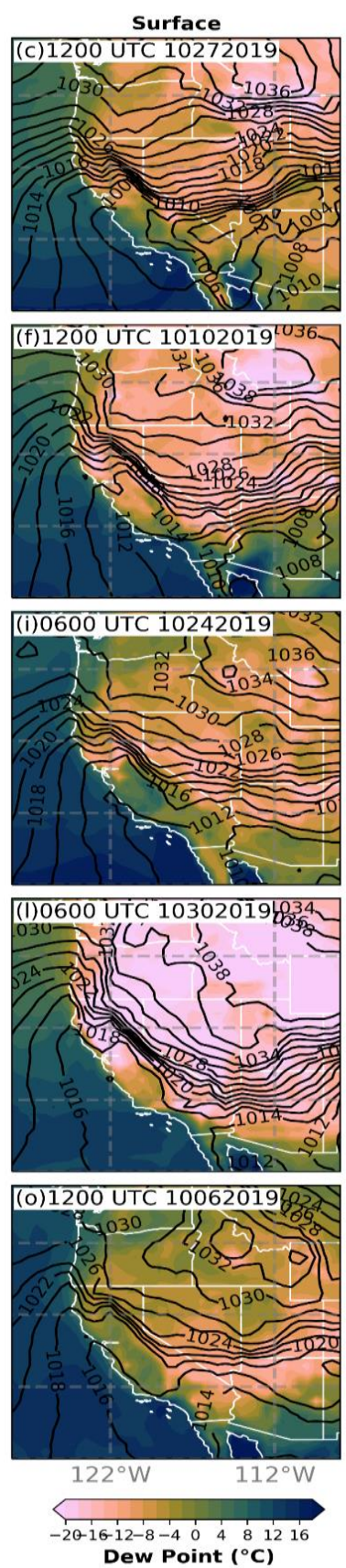

Figure 4. Synoptic overview utilizing the Global Forecast System (GFS) $0.5^{\circ}$ analysis product. Panels $(\mathbf{a}, \mathbf{b}, \mathbf{c}),(\mathbf{d}, \mathbf{e}, \mathbf{f}),(\mathbf{g}, \mathbf{h}, \mathbf{i}),(\mathbf{j}, \mathbf{k}, \mathbf{l})$, and $(\mathbf{m}, \mathbf{n}, \mathbf{o})$ correspond to WE1, WE2, WE3, WE4, and WE5, respectively. On the (left) is $500-\mathrm{hPa}$ geopotential height contours $(\mathrm{m})$ and windspeed shaded $\left(\mathrm{m} \mathrm{s}^{-1}\right)$, (center) 850$\mathrm{hPa}$ geopotential height contours $(\mathrm{m})$ and temperature advection shaded $\left({ }^{\circ} \mathrm{C} / 6\right.$ hours), (right) mean sea level pressure contours (hPa) and two meter dew point shaded $\left({ }^{\circ} \mathrm{C}\right)$. 
The vertical profile upstream just prior to the onset of WE1 showed significantly dry air throughout the entire column (Figure 5a). A stable layer was present near $800 \mathrm{hPa}$ which was observed as a temperature inversion. Just below this stable layer the wind was directed from the North and backed abruptly to westerly flow which dominated the rest of the column. The downstream profile from OAK, 12 hrs later at 1200 UTC, revealed that the column had dried considerably except for a shallow layer of mid-level moisture just above $800 \mathrm{hPa}$ (Figure 5f). This mid-level moisture was associated with a strong inversion and a layer of strong directional wind shear that abruptly backed above the inversion. A shallow moist layer was also observed at the surface but was attributed to the local marine layer. The onset of the event had only begun less than $6 \mathrm{hrs}$ before the Oakland sounding and this was not evidence of this event failing to remove effects of the marine layer. Rather, it was indicative of a delayed onset of the dry windy conditions in the low elevations. Surface observations at KOAK recorded the removal of the marine layer with an abrupt decline in $\mathrm{RH}$ that was simultaneous with the Oakland sounding (Figure 4i). Within $2 \mathrm{hrs,}$ the surface $\mathrm{RH}$ dropped from over $90 \%$ to below $23 \%$ by 1250 UTC 27 October (Figure 3i). The coarse temporal resolution of standard NWS soundings limited a detailed analysis of the event onset; therefore, Doppler lidar observed vertical wind profiles were utilized for a more detailed view of the event onset.

The lidar was deployed at 0720 UTC in the Wine Country (Figure 1b) and began DBS wind profiling scans approximately 3 min prior to the onset of the 
downslope surface winds. Just prior to the onset, while surface winds were light and variable (Figure 6e), the lidar measured a low-level wind speed maximum of approximately $30 \mathrm{~m} \mathrm{~s}^{-1}$ at $400 \mathrm{~m}$ above ground level (AGL) (Figure 6a). Minutes later, the lowest reliable range gate at $75 \mathrm{~m} \mathrm{AGL}$ measured winds greater than $18 \mathrm{~m} \mathrm{~s}^{-1}$. The lidar has a blind region of $75 \mathrm{~m}$ due to contamination of the outgoing pulse. The vertical profile was dominated by winds from the northnortheast that were backing with height. The low-level maxima persisted mostly in the lowest $500 \mathrm{~m}$ AGL while a return flow aloft developed above $700 \mathrm{~m}$ AGL. This return flow was characterized by a $180^{\circ}$ wind reversal that briefly exceeded $10 \mathrm{~m} \mathrm{~s}^{-1}$. It began at approximately 0757 UTC 27 October and was short lived, 20 min (Figure 6b,c). The observed low-level maximum accompanied by return flow aloft suggests the development of a jump-like feature. The erosion of the return flow preceded intensification of the low-level maximum that exceeded an impressive $35 \mathrm{~m} \mathrm{~s}^{-1}$ (Figure 6c,d). Sustained winds at the surface attained a maximum of $32 \mathrm{~m} \mathrm{~s}^{-1}$ which was observed nearby more than four hours later. These observations suggest that vertical wind profiling during such wind events will benefit forecasts with a lead time on when the strongest winds will reach the surface. 

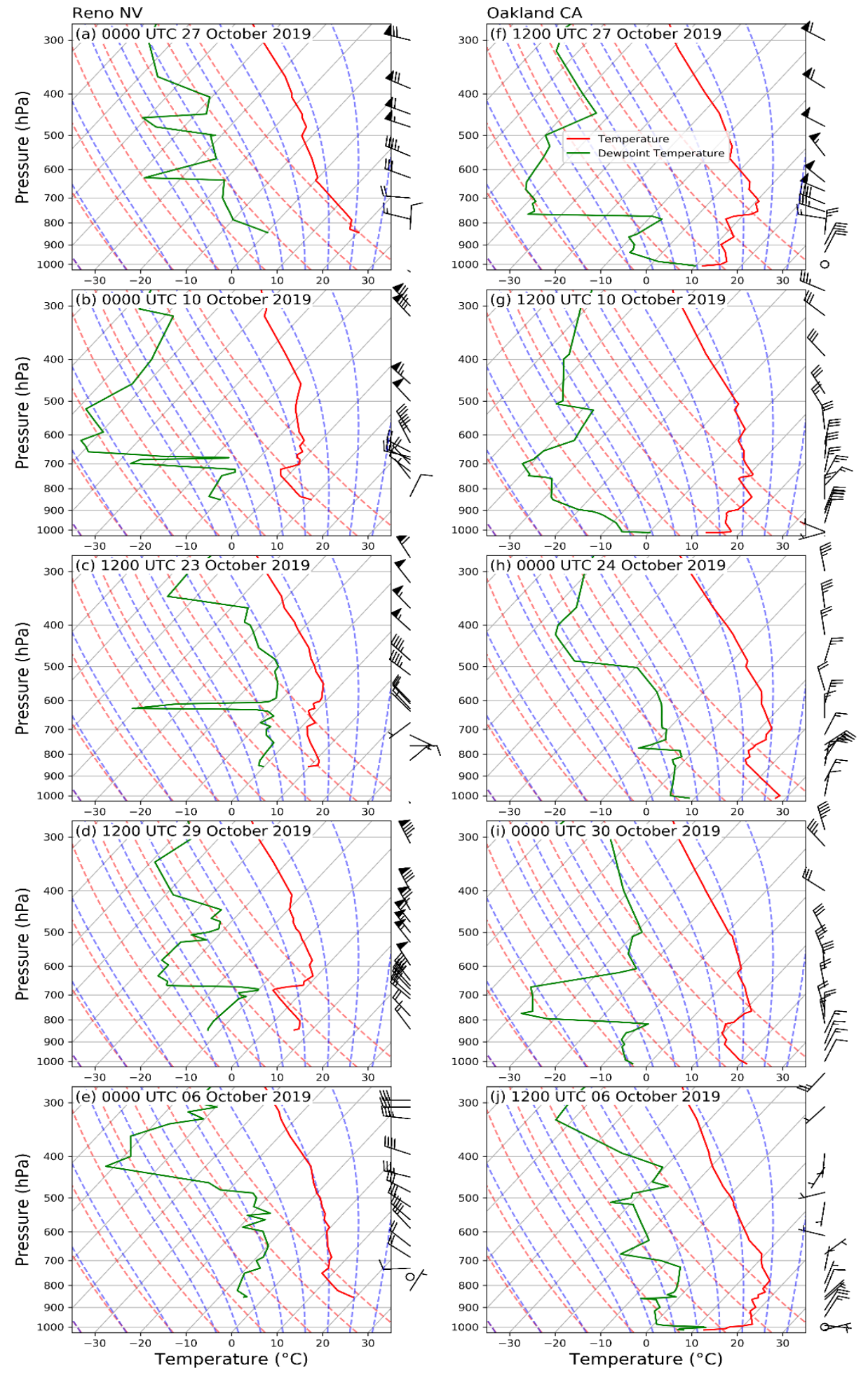

Figure 5. NWS soundings from Reno Nevada $(\mathbf{a}, \mathbf{b}, \mathbf{c}, \mathbf{d}, \mathbf{e})$ and Oakland California $(\mathbf{f}, \mathbf{g}, \mathbf{h}, \mathbf{I}, \mathbf{j})$. 

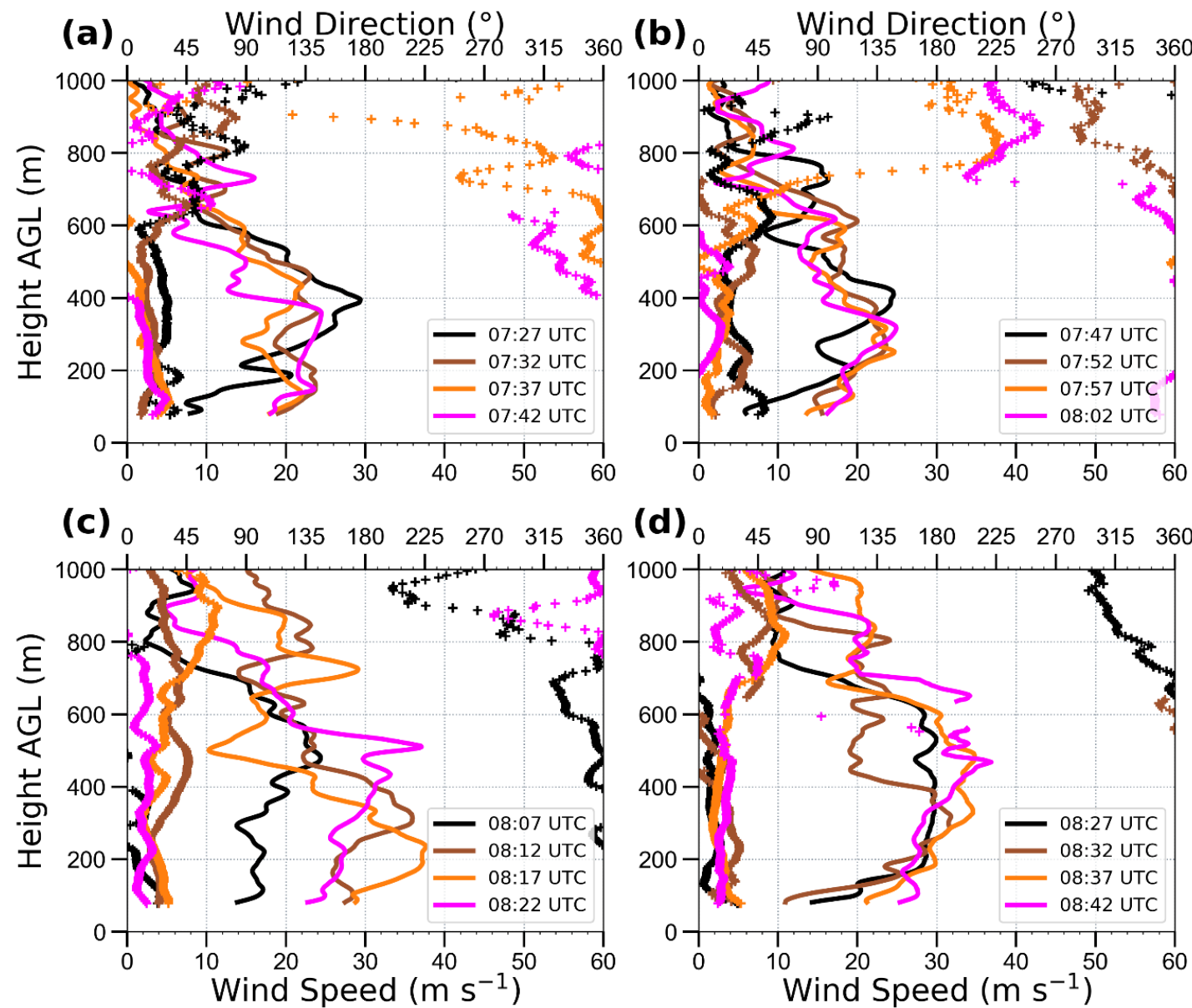

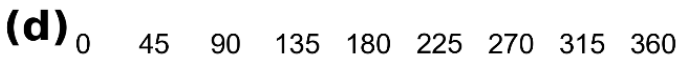

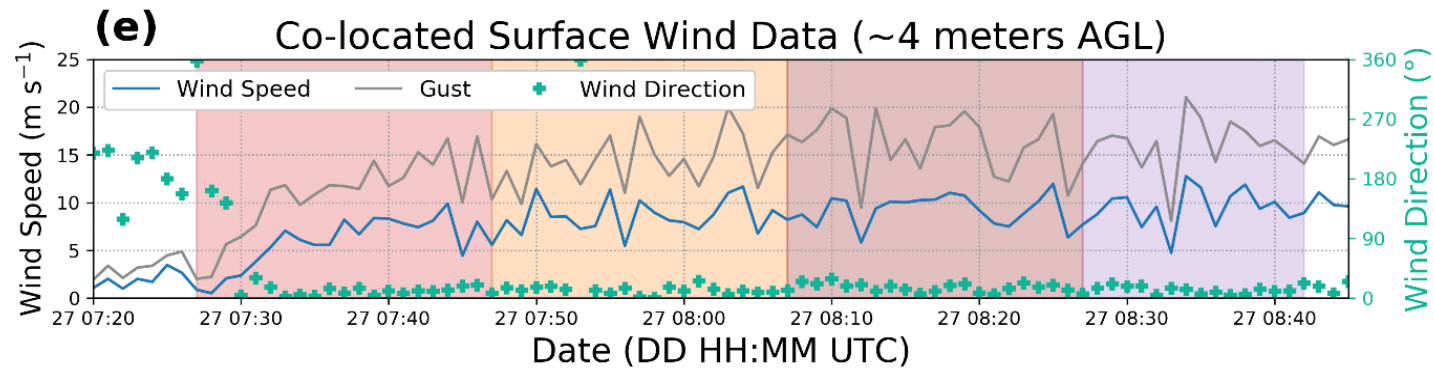

Figure 6. Data furnished from the CSU-MAPS deployment 27 October 2019. All mobile assets were positioned as specified in Figure 1b. Panels (a), (b), (c), and (d) are lidar retrieved vertical profiles that coincide with surface observations in (e) differentiated by red, orange, brown, and purple shading, respectively. Lidar observations $(\mathbf{a}, \mathbf{b}, \mathbf{c}, \mathbf{d})$ have wind speed represented by solid lines which is referenced to the lower $\mathrm{x}$-axis, and plus symbols represent wind direction which is referenced to the upper $x$-axis; colors denote discrete scans that are labeled accordingly in the legend. Surface observations (e) include sustained wind speed, gusts, and direction depicted by a solid blue line, sloid gray line, and teal plus symbols, respectively. 


\section{b. Wind event 2 (WE2)}

WE2 had roughly a $25 \%$ decrease in affected customers compared to WE1 yet almost 750,000 suffered from grid de-energization (Table 1). This event observed sustained winds in excess of $30 \mathrm{~m} \mathrm{~s}^{-1}$ in the higher elevations with gusts surpassing $20 \mathrm{~m} \mathrm{~s}^{-1}$ in the mid elevations (Figure 7). Many sites observed a sharp decrease in $\mathrm{RH}$ into the single digits associated with the onset of these strong winds. The very dry air was observed amongst all elevations but was exacerbated in the lowest elevations which was attributed to adiabatic drying.

(a) PG132
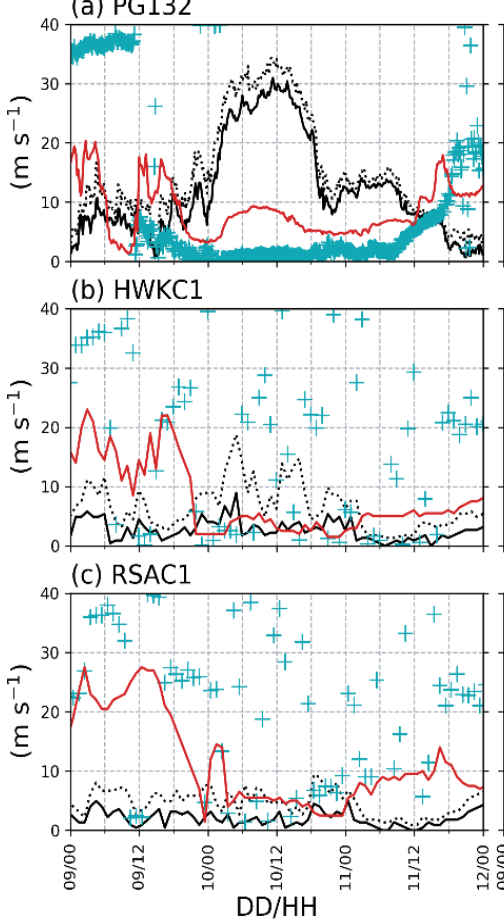

(d) DUCCl

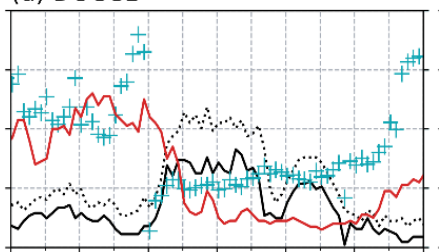

(e) PKCCl

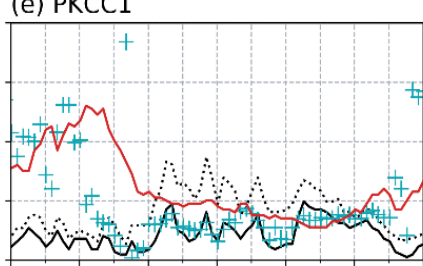

(f) PLTCl

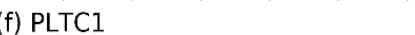

(g) SJS02

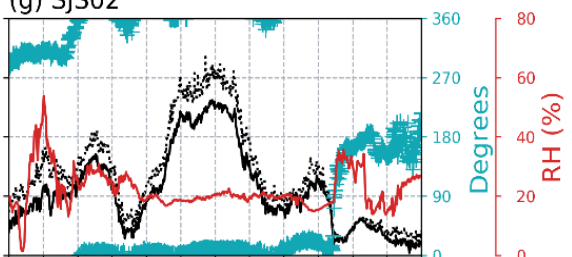

(h) ONOC1

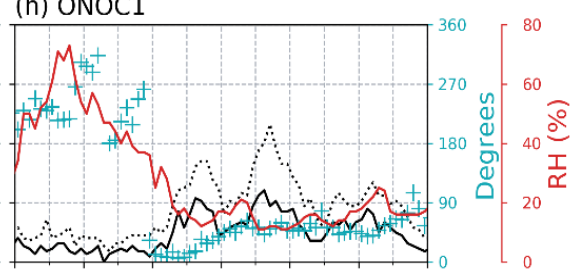

(i) KOAK

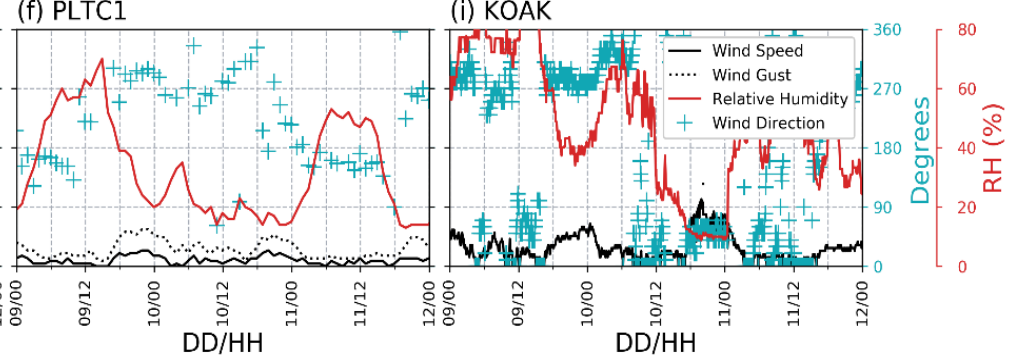

Figure 7. As in Figure 3, but focused on WE2.

The event evolved with behavior typical of downslope windstorms [30]. The most interesting observation occurred in the Bay Area. Oakland North, situated in the mid elevations, observed its peak gusts in excess of $20 \mathrm{~m} \mathrm{~s}^{-1}$ after the 
winds aloft weakened well below this magnitude. Also unique was the stark decrease in sustained wind speed between PG132 and HWKC1 (Figure 7a,b). Neither the Sierra nor the Bay area region observed this sharp decrease of winds with decreasing elevation. This was likely attributable to decreased mountain wave activity in Wine Country during WE2, but this cannot be affirmed without the aid of numerical simulations. The synoptic support for WE2 was dominated by a shortwave trough that propagated directly over the Great Basin. The 500 $\mathrm{hPa}$ geopotential heights aligned parallel to the California coast but were situated significantly further east than during WE1 (Figure 4d). Low level CAA was present at $850 \mathrm{hPa}$ with a maximum of about $5^{\circ} \mathrm{C}$ per $6 \mathrm{hrs}$ and was centered over northern California during the peak of the event (Figure 4e). At the surface, an inverted trough developed over coastal California in conjunction with high pressure that spanned across much of the Great Basin (Figure 4f). Similar to WE1, a tight surface pressure gradient developed along the Sierra Nevada as well as across northern California and was associated with surface dewpoint temperatures of $-20^{\circ} \mathrm{C}$ (Figure $\left.4 \mathrm{f}\right)$.

The upstream vertical profile from Reno, NV indicated extremely dry air above $700 \mathrm{hPa}$ with a slight increase in moisture in the mid to lower levels (Figure 5b). The dewpoint depression associated with this mid-level moisture reached a minimum of approximately $10^{\circ} \mathrm{C}$ and was aligned with a strong temperature inversion. Below the inversion, winds were $10 \mathrm{~m} \mathrm{~s}^{-1}$ from the north-northeast and backed rapidly to a north westerly flow aloft. This directional shear occurred near 
the height of the stable layer and is evidence of flow from the Great Basin over the Sierra Nevada indicating the event was underway. Twelve hours later, 1200 UTC 10 October, the vertical profile at Oakland was extraordinarily dry throughout the entire column (Figure $5 \mathrm{~g}$ ). Multiple temperature inversions were present; and excluding the surface nocturnal inversion, the most dominant inversion was at $900 \mathrm{hPa}$. This added context to the speculation of decreased mountain wave activity in the Wine Country region during WE2. An altitude of $900 \mathrm{hPa}$ was roughly $1000 \mathrm{~m}$ and incidentally below many of the ridge lines in the Wine Country which possibly inhibited mountain wave activity and subsequent progression of downslope winds. However, this inversion was above the lower ridgelines of the Bay Area and supported mountain wave activity and progression of winds downslope. This observation supported conceptual models that emphasize the importance of the height and depth of the stable layer and the resulting evolution of any potential downslope event $[31,32]$.

Also observed in Oakland's sounding was surface moisture which was surprising since the event had moderate to strong intensity and had begun more than $12 \mathrm{hrs}$ prior (Figure $5 \mathrm{~g}$ ). It was also interesting that the sounding observed wind from the west at this time. It is speculated this was a result of the marine boundary layer intruding into the region, or due to the development of a rotor-like circulation at the base of the topography. However, it is unlikely that onshore flow from the marine layer would have persisted coincident with sustained winds just upslope in excess of $10 \mathrm{~m} \mathrm{~s}^{-1}$ and gusting higher KOAK surface station 
confirmed that the onset of the wind event at the surface occurred more than 18 hrs after the event began in the high elevations (Figure 7i,g). RH fluctuated between $70 \%-20 \%$ before the extremely dry air extended to the base of the topography (Figure 7i). The complex behavior of atmospheric drying among different elevations, again emphasizes the importance of the atmospheric profile and the need for high temporal resolution observations. Above the shallow marine layer (Figure $5 \mathrm{~g}$ ), a very dry profile was observed with no evidence of the previous mid-level moisture observed $12 \mathrm{hrs}$ earlier in the Reno sounding. The driest layer of the profile was observed at $700 \mathrm{hPa}$ with a dew point depression of $\sim 50^{\circ} \mathrm{C}$.

\section{c. Wind event 3 (WE3)}

Significant winds were produced by WE3; however, these were mostly localized to the mid and higher elevations. Gusts above $20 \mathrm{~m} \mathrm{~s}^{-1}$ were consistently observed near crest height in all three regions (Figure 8). The Wine Country was the only region to have experienced significant wind in the lower elevations which consisted of gusts exceeding $15 \mathrm{~m} \mathrm{~s}^{-1}$. Single-digit $\mathrm{RH}$ was observed on multiple occasions and most of the event observed $\mathrm{RH}$ between 10 $20 \%$ amongst all elevations. Further, the fire weather potential was confirmed with the ignition of the Kincade fire late on 23 October which rapidly consumed thousands of acres [33]. WE3 evolved similarly to WE1 in the Wine Country where dry gusty winds were observed at all elevations in the lee of the Mayacamas Mountains (Figure 8a,b,c). In contrast, the Sierra and Bay Area 
regions did not observe significant wind gusts at the lower elevations. Also, the low elevation site in the Sierra region (PLTC1) observed weak winds with a maxima in wind speed of $<10 \mathrm{~m} \mathrm{~s}^{-1}$ that occurred at the onset and end of the event (Figure 8f). Also, these weak winds shifted from westerly to eastsoutheasterly during the event. This indicates the complexities in the observed surface winds during this event.

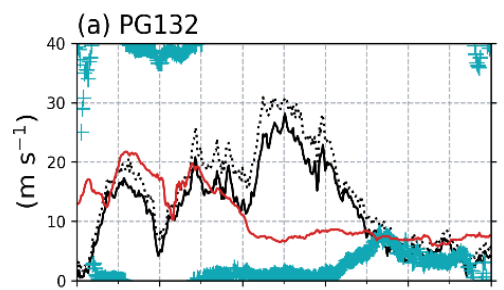
(d) DUCC1

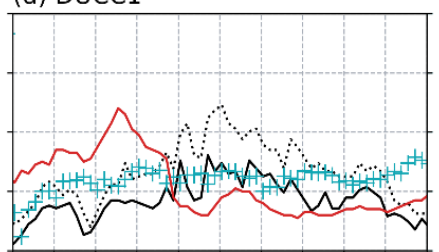

(g) SJS02

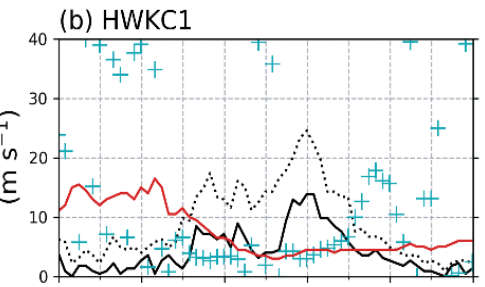

(e) PKCC1
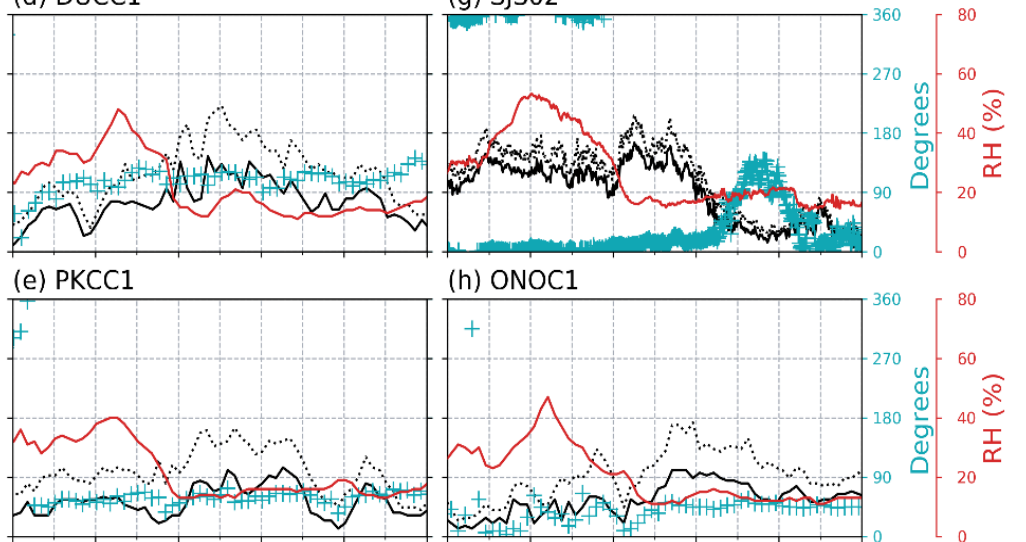

(h) ONOC1
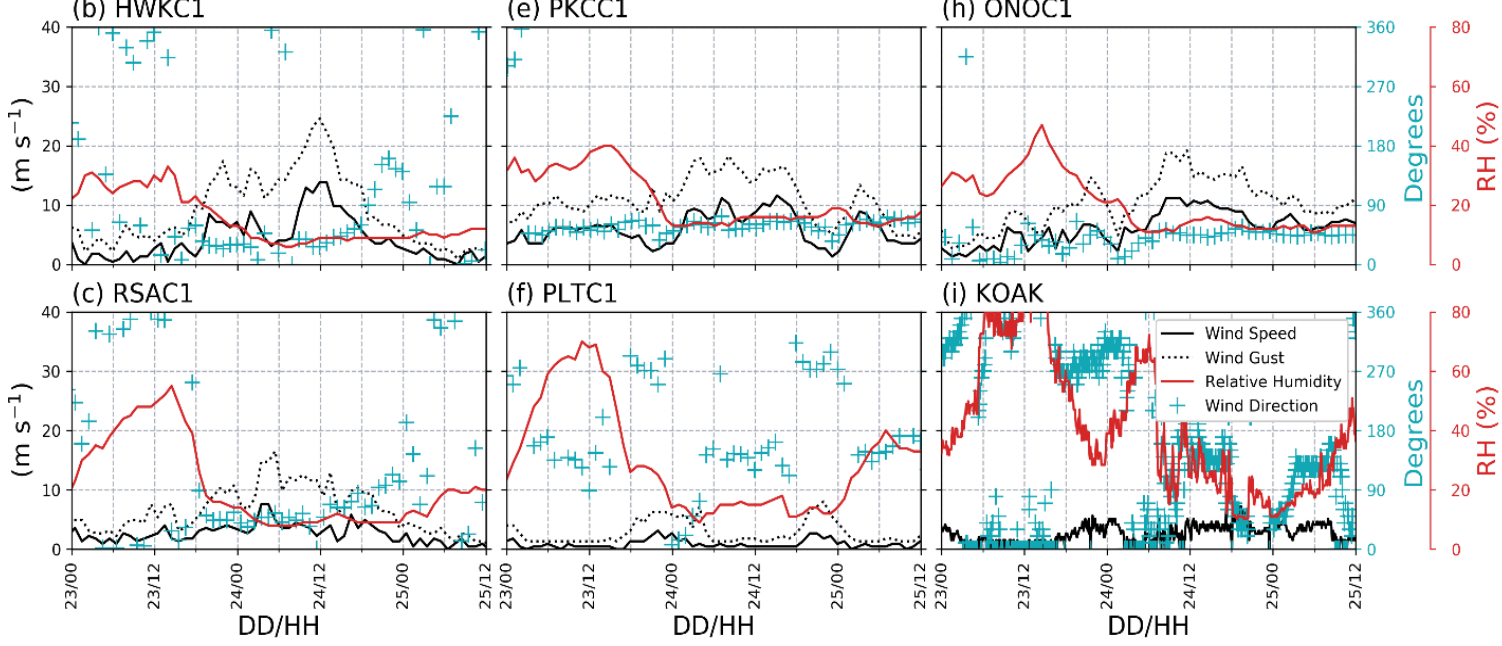

(f) PLTCl
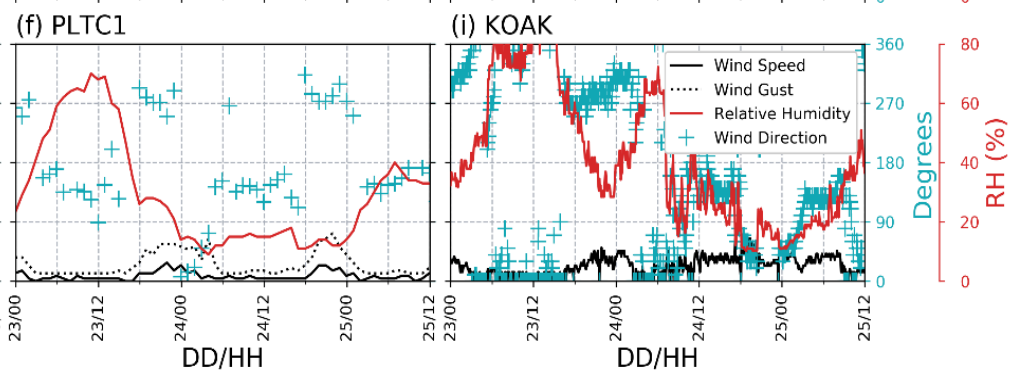

Figure 8. As in Figure 3, but focused on WE3.

The synoptic environment that drove WE3 was an upper-level shortwave trough that amplified over the eastern Great Basin (Figure 4g). This was accompanied by moderate low-level CAA oriented parallel to the California coast (Figure 4h). A strong surface pressure gradient, yet less superior to WE1 and 
WE2, developed along the Sierra Nevada and across northern California accompanied by moderately low dew point temperatures (Figure 4i).

The upstream profile at Reno, NV preceding WE3, indicated a very different profile from the other events. Preceding this event, the sounding observed generally moist conditions through much of the profile with one exception between 600 and $700 \mathrm{hPa}$ (Figure 5c). This layer had a dew point depression of about $40^{\circ} \mathrm{C}$ which was much larger than the profile mean of $10^{\circ} \mathrm{C}$. At $700 \mathrm{hPa}$, a temperature inversion was present and below this layer the winds were from the east-northeast and backed above the inversion. This backing pattern was not as prevalent in the downstream profile at Oakland where the winds were generally northerly throughout the profile (Figure $5 \mathrm{~h}$ ). The exception was northeast flow near the inversion that produced a local wind maximum. The inversion height was roughly $800 \mathrm{hPa}$ which was notably higher than observed in WE2. This profile also acknowledged that WE3 was a significantly warmer event than others analyzed, both at the surface and through the profile (Figure 5h). The observed dewpoint depression through the column increased substantially from the upstream Reno profile (Figure 5h). This was attributed to the shortwave trough advecting a drier airmass into the region and adiabatic descent.

\section{d. Wind event 4 (WE4)}

WE4 was associated with the same PSPS as WE1. It commenced approximately 24 hrs after WE1 ceased which resulted in an average deenergization length of 55 hours for affected customers [19]. The wind intensity 
was not exceptional as had been observed days prior during WE1. The atmospheric moisture was, however, incredibly low and produced single-digit $\mathrm{RH}$ values across all three regions. The event evolved with a two-phase evolution as previously discussed. During this event, the high-altitude sites (Figure 3a,g) observed a decrease in winds at 0000 UTC 30 October 2019. Simultaneously, the mid-elevation sites observed an increase in winds (Figure 3b,h). At 1500 UTC 30 October, ONOC1 observed NE winds in excess of $10 \mathrm{~m} \mathrm{~s}^{-1}$ while the higher elevation site (SJS02) observed south winds of $\sim 5 \mathrm{~m} \mathrm{~s}^{-1}$ (Figure 3h,g). This observation acknowledges another complexity of offshore wind events where their cessation in the elevated terrain does not strictly denote the end of the event regionally.

Synoptically, WE4 was comparable to WE2, however, WE4 did not produce winds that were as extraordinary as observed during WE2. The shortwave trough associated with WE4 (Figure 4j) was more pronounced and extended further south as compared to WE2 (Figure 4d). It should also be noted that this event had much more significant impacts to southern California than northern California, namely the Santa Ana Winds were much more pronounced than the North and Diablo Winds. The CAA signature at $850 \mathrm{hPa}$ (Figure 4k) was also very similar to that of WE2 (Figure 4e). The surface is where these events observed the most notable differences. WE4 had significantly colder surface dew point temperatures and the pressure gradient was stronger along the central 
Sierra Nevada and Southern California. This orientation, favoring a southward shift of the system, was attributed to the shortwaves southward extension.

The Reno sounding for WE4 observed the most robust temperature inversion of all events. It was present just above $700 \mathrm{hPa}$ (Figure $5 \mathrm{~d}$ ) and was accompanied by significant mid-level moisture, with a dewpoint depression less than $5^{\circ} \mathrm{C}$, near crest height. This sounding occurred about 6 hrs prior to the onset of WE4 and subsequently, the profile did not observe any directional shear near the inversion. Twelve hours later, approximately $6 \mathrm{hrs}$ after the onset of WE4, the Oakland sounding observed a very dry profile with a surface dew point temperature of $-5^{\circ} \mathrm{C}$. This observation occurred $6 \mathrm{hrs}$ prior to the peak of the event, and the arrival of the driest air occurred soon after this time shown in the surface conditions (Figure 3h). This further highlights the observational limitations associated with infrequent soundings.

\section{e. Wind event 5 (WE5)}

WE5 was the weakest of all events with maximum gusts narrowly exceeding $20 \mathrm{~m} \mathrm{~s}^{-1}$ and only at the high elevations. There was moderate drying associated with this event ( $\mathrm{RH}$ typically above $20 \%$ ) with a few periods becoming less than 20\%. The $\mathrm{RH}$ recovered overnight in most locations observed (Figure 9). The progression of windy conditions to lower elevations of the leeward slopes was favored in the Sierra and Bay Area regions during WE5. 


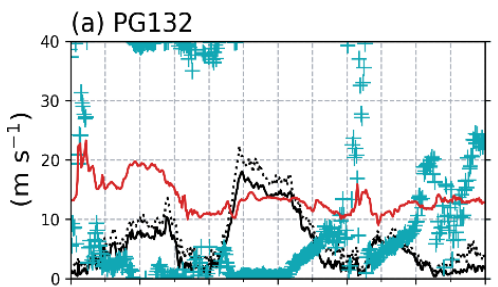

(d) DUCC1
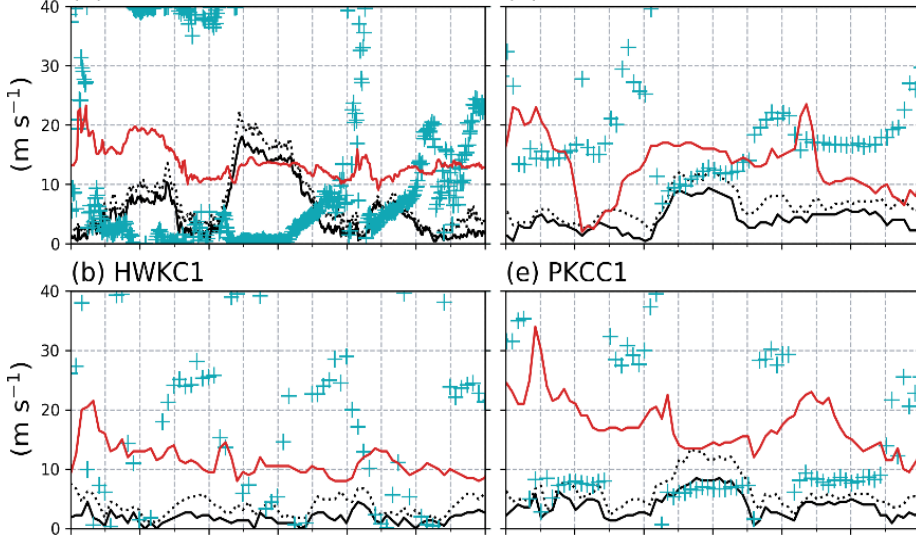

(g) SJS02

(e) PKCC1

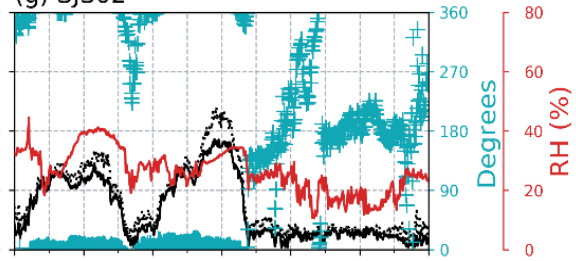

(h) ONOC1
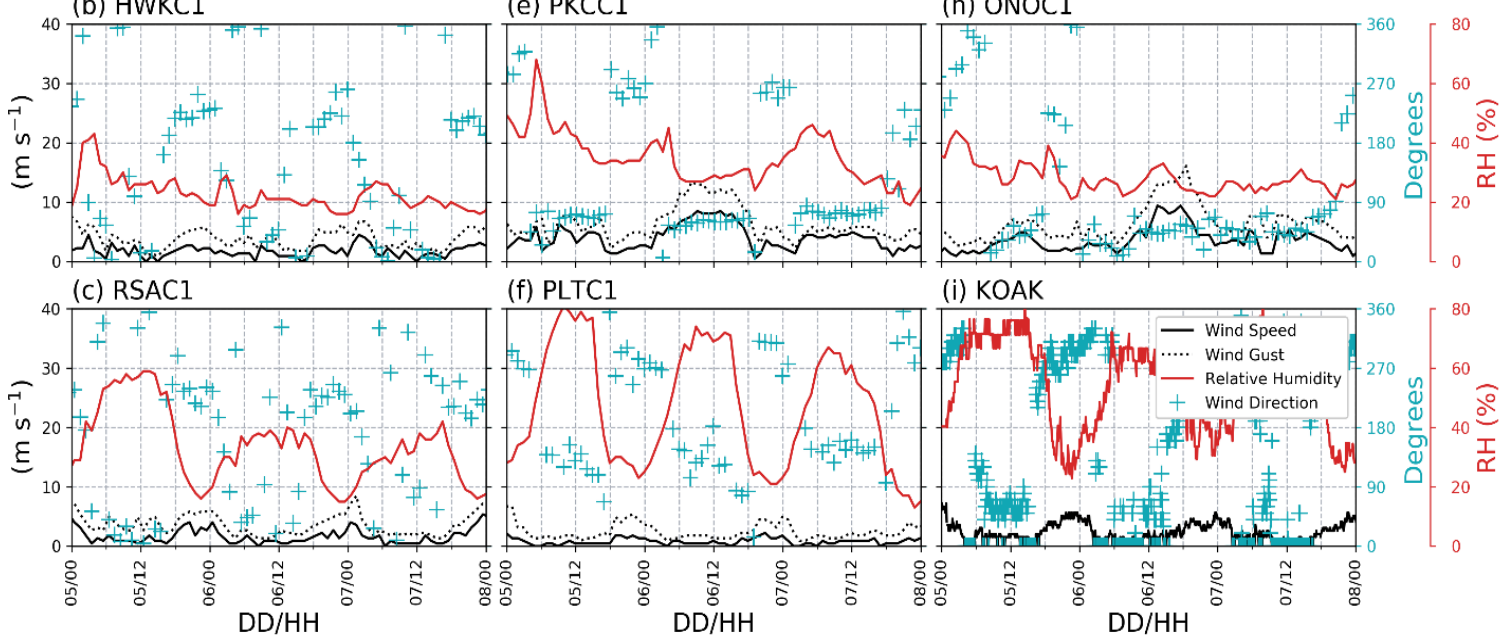

(f) PLTCl

(i) KOAK
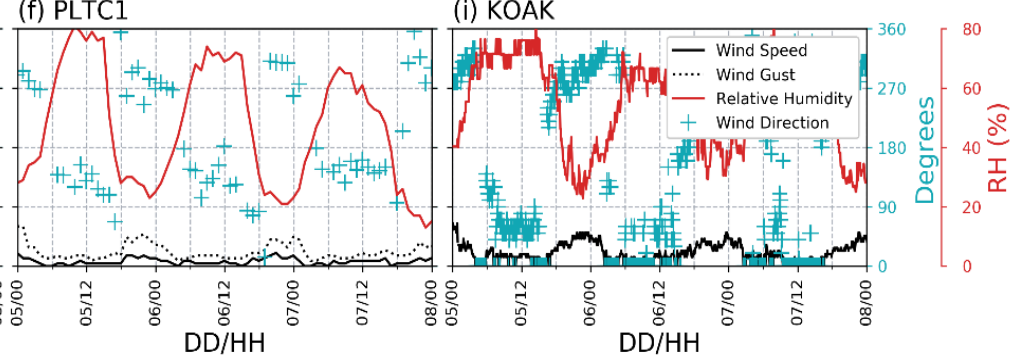

Figure 9. As in Figure 3, but focused on WE5.

The upper level shortwave trough was quite weak and propagated over the eastern side of the Great Basin (Figure 4m). The low-level CAA did not exceed $3^{\circ} \mathrm{C}$ per $6 \mathrm{hrs}$ and only a weak surface pressure gradient was observed (Figure $4 n, 0)$. Further, both upstream and downstream profiles observed temperature inversions (Figure 5e,j). The surface pressure gradient in conjunction with lowlevel CAA and an associated temperature inversion confirmed the setup was analogous to offshore wind events that exacerbate fire weather risk. However, WE5 lacked intensity which is primarily attributed to the lack of upper level support. Herein, we classify this event as a borderline event that did not exceed PG\&E thresholds at the select sites observed in this analysis. Exploitation of 
wind profilers would be of great use to better assess structural evolution of the vertical wind profile and would aid with forecasting future borderline events.

\subsection{Weather and Fuels Cumulative effect on Fire Danger}

The NFDRS output provides key indices that help evaluate fuel and weather characteristics to assess wildland fire danger. Among many other uses, RAWS have been developed to monitor weather for fire danger applications and ensure standardized data collection suitable for NFDRS [34]. Further, many NFDRS indices were designed to be used as normalized indexes where absolute values had no true meaning, but they aided in decision support when the values were normalized to regional historical archives. NFDRS's inherent design required surface stations to have substantial historical data. The surface stations utilized for the meteorological analysis were chosen for comprehensive geographic coverage throughout different regions and elevations. However, these stations did not meet all NFDRS criteria which resulted in the use of different sites for the fire danger analysis. The same framework of the meteorological analysis was kept where three stations per region were selected to comprehensively assess each region (Figure 1c). Six parameters were calculated for each site including 100-hr FMC, ERC, BI, SC, IC, and FFWI. These data were then grouped by calendar day and averaged within each region for 2019 observations as well as their respective climatological averages (Figure 10). All stations had climatological data from 2000-2018 except Openshaw which only covered 20132018. These indices follow an ordinary convention where higher values yield 
higher fire danger except for 100 -hour fuels which have an inverse relationship to fire danger. This inverse relationship is acknowledged and the 10th percentile has been calculated for 100 -hour fuels as opposed to the 90th percentile for all other indices. However, this was ignored for descriptive analyses and 100-hour FMC observations that transcended below the 10th percentile were referenced to as exceeding the 90th percentile. ERC and 100-hour FMC were the only indices not directly affected by wind and these indices consequently observed less variability among PSPS events. All other indices that are directly affected by wind observed abrupt spikes during most PSPS events, and two spikes during the last PSPS of October that was indicative of WE1 and WE4. 

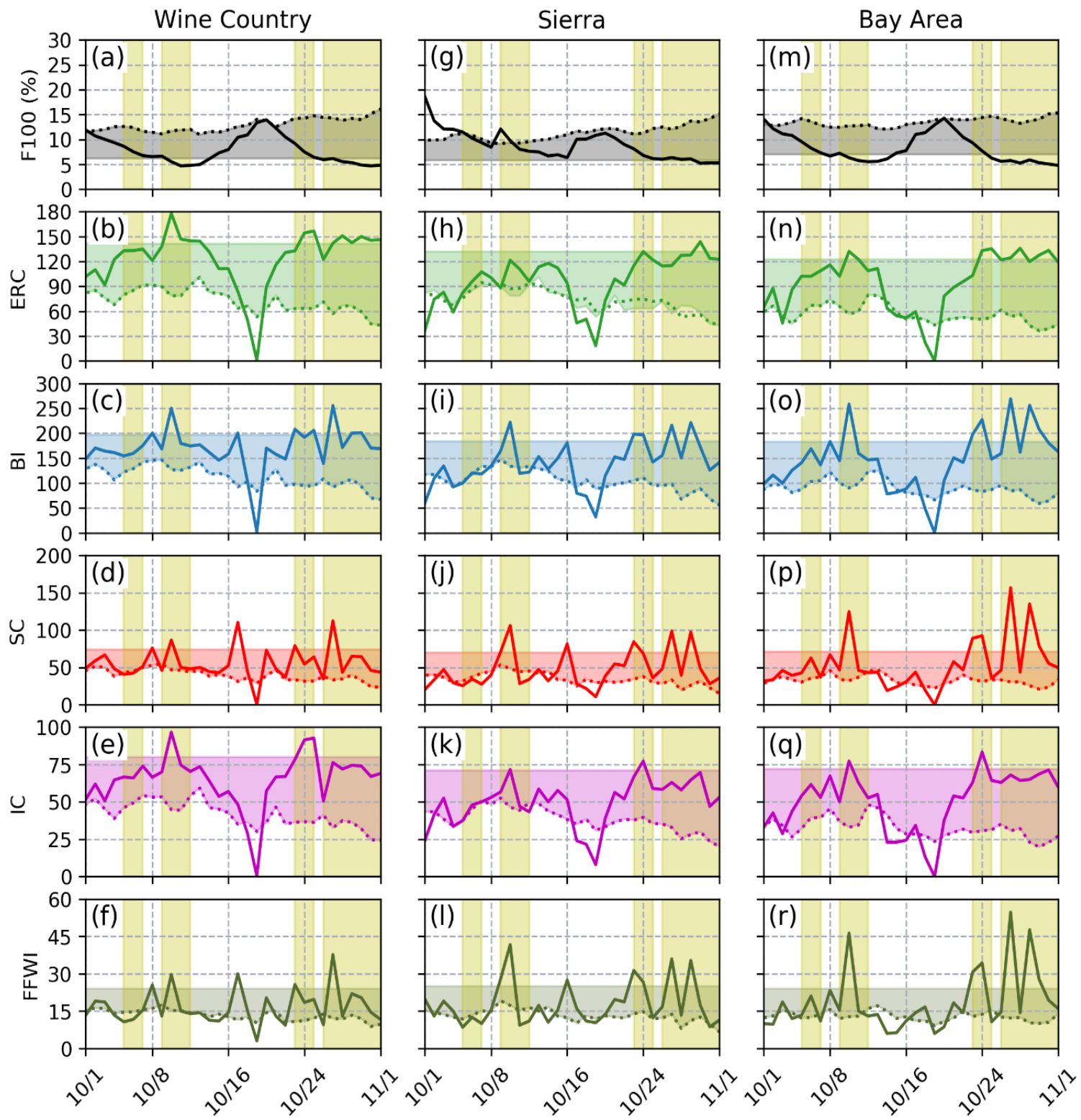

Figure 10. The yellow shaded regions depict PSPS outages. The dotted and solid lines represent the regional climatic average and the regional 2019 average, respectively. The color shading above (below) each dotted line extends to the $90^{\text {th }}\left(10^{\text {th }}\right)$ percentile of October observations for each respective region and parameter (F100). The Wine Country region utilizes data from Konocti, Hawkeye, and Santa Rosa. The Sierra region utilizes data from Openshaw, Pike County Lookout, and Saddleback. The Bay Arear region utilizes data from Oakland North, Briones, and Las Trampas. All regional climactic averages are calculated using the period 2000-2018 except Openshaw was 2013-2018. 
The highest fire danger during WE1 was observed in the Bay Area where all indices except IC exceeded the 90th percentile (Figure 10m,n,o,p,q,r). This means that these conditions were more conducive to high fire danger than $90 \%$ of all October conditions for the Bay Area from 2000-2018. All indices of all regions during WE2 exceeded the 90th percentile except the Sierra region's ERC and 100-hour FMC (Figure 10g,h). The subordinate fire danger indicated by these two observations were linked to above average 100-hour FMC during WE2 (Figure 10g). WE3 observed elevated fire danger, but the index values were inferior to those observed in WE1 and WE2. Though IC was an outlier which observed its maximum quantities during WE3 when compared to other wind events (Figure 10e,k,q). In examining the equation for IC, it was discovered that a key input is the heat required for ignition which is dependent on the ambient atmospheric temperature. WE3 was significantly warmer than the other wind events analyzed and led to maximum IC. Two wind events occurred in the week prior to WE4 and fuels continually dried with no little to no moisture recovery (Figure 10a,g,m). This led to anomalously dry fuels during WE4 and indices that were more heavily dependent on fuel condition, such as $\mathrm{BI}$ and $\mathrm{SC}$, were significantly higher during WE4 than other indexes (Figure 10i,j,o,p). A lack of strong winds observed in the Wine Country during WE4 was indicated by the FFWI (Figure 10f), and as a result the BI and SC in this region (Figure 10c,d) did not spike as was observed in the Sierra and Bay Area regions. WE5 did not generate a single $90^{\text {th }}$ percentile observation among all indices of all 
regions. The lack of fire danger observed coincident with synoptic ingredients conducive for downslope winds reinforced our claim that WE5 was a borderline event.

A noteworthy trend of 100 -hour FMC was observed over the period of interest. A rain event of less than $5 \mathrm{~mm}$ occurred on 19 October 2019, and according to NFDRS the 100-hour FMC briefly improved to near average conditions. This brief increase preceded an overall downward trend through the end of the month. This downward trend was exacerbated by three wind events within one week which caused 100-hour fuels in the Bay Area to decrease to the lowest 1 percentile. This observation clearly portrayed how fire danger conditions do not reach their top $1 \%$ most dangerous conditions through any single event, but rather through a culmination of high fire danger events with minimal relief between them. This point should be pressed regarding the weak precipitation event in mid-October. Had this precipitation been absent, the fire danger conditions could have been exponentially greater by the end of October than what was observed.

\subsection{Discussion and Summary}

The state of the fuels, weather conditions, and fire danger environment have now each been thoroughly discussed. However, the complex weather behavior and its potential for rapid wildfire spread needed a more concise quantification. Quantification of elevated weather induced fire potential that promote rapid fire spread, given an ignition, was needed to summarize the conditions of each 
event. The wind events observed displayed many similarities to Santa Ana winds and our analysis was interested in the comparison between each event. Also, it has been shown that the large fire potential (LFP $\left.\mathrm{w}_{\mathrm{w}}\right)$ provided greater contrast among Santa Ana and non-Santa Ana events than the classic Fosberg Fire Weather Index (FFWI) [35]. Therefore, the $\mathrm{LFP}_{\mathrm{w}}$ was used to summarize the weather conditions of each event. The $\mathrm{LFP}_{\mathrm{w}}$ is a fire weather index which is the product of a constant $(0.001)$, the sustained wind speed squared, and the dewpoint depression [35].

The $\mathrm{LFP}_{\mathrm{w}}$ was calculated for the extent of each wind event and the maximum was extracted from each site for each wind event (Figure 11). The index clearly illustrated the general decrease in large fire potential associated with decreasing elevation among all regions. WE1 observed the strongest sustained wind speeds, but WE2 was associated with less atmospheric moisture. As a consequence of the differences in moisture, the maximum LFP $\mathrm{w}_{\mathrm{w}}$ was observed during WE2 for the Wine Country and Bay Area (Figure 11a,c). This indicates the index's ability to assess the combination of impacts from wind and atmospheric moisture and was advantageous for exposing other event intricacies. Further, LFP ${ }_{\mathrm{w}}$ for WE1 was less than that of WE2, WE3, and WE4 in the Sierra region which seemed counterintuitive as WE1 was observed to be the most intense event (Figure 11b). This observation is likely associated with the pressure gradient associated with each event (Table 2). WE1 observed a strong northerly pressure gradient (RDD-SAC) while only a modest offshore gradient 
(SFO-WMC) was observed. Evidence that these offshore events have different flavors which favor different regions of vulnerability based on fundamental event characteristics. Also interesting was the overall lower values of $\mathrm{LFP}_{\mathrm{w}}$ observed in the Sierra region (Figure 11b) as opposed to the Wine Country and Bay Area regions (Figure 11a,c). This observation insinuated that the Sierra region was less impacted by the wind events analyzed which is perhaps a caveat of our analysis. We have summarized the entire Sierra region using only three surface stations, but this region is vast and known to have localized channeling effects in specific corridors such as the Feather River Canyon.

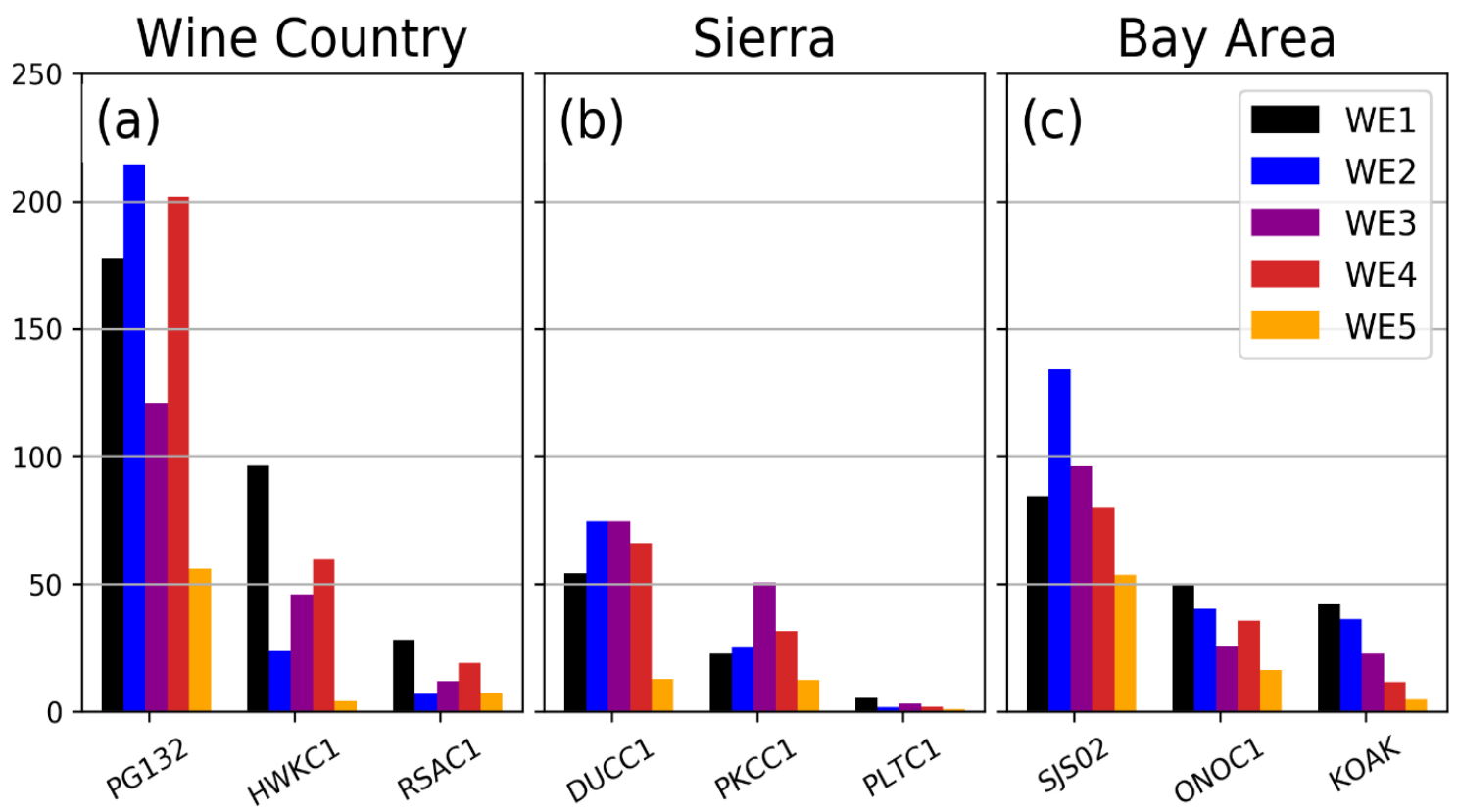

Figure 11. The maximum $L_{F P}$ for each site during each wind event and grouped by region. See Figure 1 for geographic overview of sites. LFP $\mathrm{w}_{\mathrm{w}}$ is a unitless index that only considers weather variables and higher values indicate higher potential for large fires.

More regarding WE2 was the sharp decrease in $\mathrm{LFP}_{\mathrm{w}}$ between PG132 and HWKC1 during WE2 which highlighted the lack of valley impact in the Wine 
Country (Figure 11a). This sharp decrease with decreasing elevation was isolated to WE2 in the Wine Country. It is speculated that the lack of valley penetration for WE2 in the Wine Country was due to limited mountain wave activity. Transition to observations of WE3 when LFP ${ }_{w}$ at PKCC1 was most superior (Figure 11b) with the secondary maximum observed during WE4. This identified a flavor of offshore event which produced the most impacts to the mid elevations of the Sierra region. The offshore flavor with reference to event characteristics of a modest northerly gradient (RDD-SAC) coincident with a strong offshore gradient (SFO-WMC) which WE3 and WE4 observed (Table 2). Maximum LFP $\mathrm{w}_{\mathrm{w}}$ observed during WE4 was exceptionally high in the Wine Country (Figure 11a). An incredibly dry air mass (Figure 3L) associated with this wind event contributed to the large LFP $\mathrm{w}_{\mathrm{w}}$ and the consequential significance of WE4's impacts. Further, multiple wind events transpired in the week prior to WE4 which had a cumulative effect on drying the fuels. Finally, LFP $\mathrm{w}_{\mathrm{w}}$ only observed elevated fire weather along the ridgetops of the Wine Country and Bay Area during WE5 (Figure 11a,c). This observation assisted in recognizing the minimal intensity and spatial extent of WE5 and supports our claim that it was a borderline event.

In summary, the public safety power shutoffs in October 2019 occurred during periods of offshore flow. Offshore flow events are notorious for increased fire weather potential, but did each event produce conditions consistent with the criteria PG\&E had determined for de-energization? Shortly put, yes, in all cases 
at least one of the weather thresholds regarding wind or humidity was exceeded in conjunction with dry fuels. However, the weakest of the events, WE5, only marginally produced these conditions and they were short lived as well as localized to high elevations. Further, WE5 was the only event that did not observe $90^{\text {th }}$ percentile fire danger conditions. However, some event details specifically pertaining to WE2 remain a mystery; such as the stark decrease of windspeed with decreasing elevation in the Wine Country region. This motivated the use of numerical simulations to observe differences in mountain wave activity among each event. 


\section{Chapter 2 Numerical Simulations of the October 2019 PSPS events}

\subsection{Introduction}

The most destructive fires in California, prior to 2020, occurred during downslope windstorms $[1,7,9]$. The record setting destruction began with the Tubbs Fire of 2017 and was then surpassed by the deadly Camp Fire of 2018. Amid these devastating events, Pacific Gas \& Electric (PG\&E) adopted a newer procedure in 2018 called a public safety power shutoff (PSPS). Soon after, Cal Fire determined PG\&E responsible for the ignition of the 2018 Camp Fire [2], and during the following fire season of 2019 PG\&E initiated seven PSPSs [19]. Most of the 2019 PSPSs occurred during offshore flow events which can locally stimulate downslope windstorms called Diablo Winds. Mountain wave activity during Diablo Wind events can develop strong gusty winds that favor the leeside slopes. The three mechanisms for the onset of downslope windstorms include hydraulic jumps, large-amplitude vertically propagating lee waves, and wave breaking [12]. Numerical simulations are the primary forecast tool for such events and are evidently required to analyze mountain wave behavior.

The uncertainties within the weather research and forecast model (WRF) are inherently important for implementation of PSPS events. The PG\&E operational mesoscale modeling system (POMMS) utilizes a 3km WRF as a primary forecast tool for PSPS decision making [36]. POMMS is accompanied by a 30 -year downscaled climatology that allows for detailed historical event comparisons. Other operational forecast tools with similar horizontal resolutions include the 
NAM Nest and Hi-Resolution Rapid Refresh (HRRR) which are provided by NCEP. Movements towards increased horizontal resolutions introduced the experimental NAM Fire Weather Nest with $\sim 1 \mathrm{~km}$ horizontal resolution [37]. Finer horizontal resolutions with operational numerical simulations was a direct result of computing resource advancements. As advancements in computing resources persist, the already abundant amount of available data will skyrocket.

Many case studies have utilized WRF to simulate downslope windstorms $[7,9,28,38,39]$. The area of interest during the PSPS events was previously analyzed [9], but Bower's WRF simulations lacked an upgrade from the default static terrain data. Mountain wave behavior is strongly influenced by complex terrain; therefore, high resolution terrain data may be a crucial upgrade to increase WRF's simulation performance of downslope windstorms. Further, previous studies have showed that simulation accuracy of downslope wind events had the strongest dependence on the planetary boundary layer (PBL) scheme and a secondary dependence on the land-surface model (LSM) $[7,28]$. Both Brewer and Cao documented the Asymmetric Convection Model version 2 (ACM2) PBL and Pleim-Xui LSM as superior parameterizations for their WRF simulations of downslope windstorms. However, respectable simulation performance of downslope windstorms with the Shin-Hong scale aware PBL and Noah LSM have also been documented [39]. These findings were utilized as a framework for model calibration within this study. 
During the simulation calibration process, this study examined WRF's forecast capabilities for different surface networks, explored the "gray zone" of planetary boundary layer processes, and validated the use of high-resolution numerical simulations. Upon selection of an optimum configuration, wave activity among the five observed wind events was assessed to discern differences in valley wind extent.

\subsection{Methods}

The observations in the previous chapter revealed that the valley extent was not directly related to the event intensity. It was hypothesized that these differences are a result of differences in wave dynamics during each event. Numerical simulations are leveraged to expand the analysis and assess the wave dynamics among each event. Additionally, the quality at which WRF simulates these events is important to understand the uncertainty that is present when PG\&E decides to de-energize a grid. Finally, the optimal horizontal resolution was assessed to understand if the new operational models at $1 \mathrm{~km}$ are more beneficial than the $3 \mathrm{~km}$ models (also is sub-kilometer beneficial).

An advanced research WRF (ARW) simulation was constructed with 2-way nested domains telescoping from $9 \mathrm{~km}, 3 \mathrm{~km}, 1 \mathrm{~km}$, and down to $\frac{1}{3} \mathrm{~km}$ horizontal resolution for the innermost domain (Figure 12). All domains had 80 vertical levels, and Domain 4 utilized high resolution ( $30 \mathrm{~m})$ shuttle radar topography mission (SRTM) data [40]. The process of preparing SRTM data for the WRF preprocessing system (WPS) is quite complicated [41]. Conversions, outlined by 
Beezley, to binary format for the WPS were completed with GIS4WRF [42].

Initial and lateral boundary conditions were provided by the $12 \mathrm{~km}$ NCEP North American Mesoscale (NAM) model. The innermost domain with sub-kilometer horizontal resolution was centered over the Kincade Fire (Figure 13) because of vertical data availability and high Diablo event frequency while the $1 \mathrm{~km}$ domain encompassed the entire SFBA.

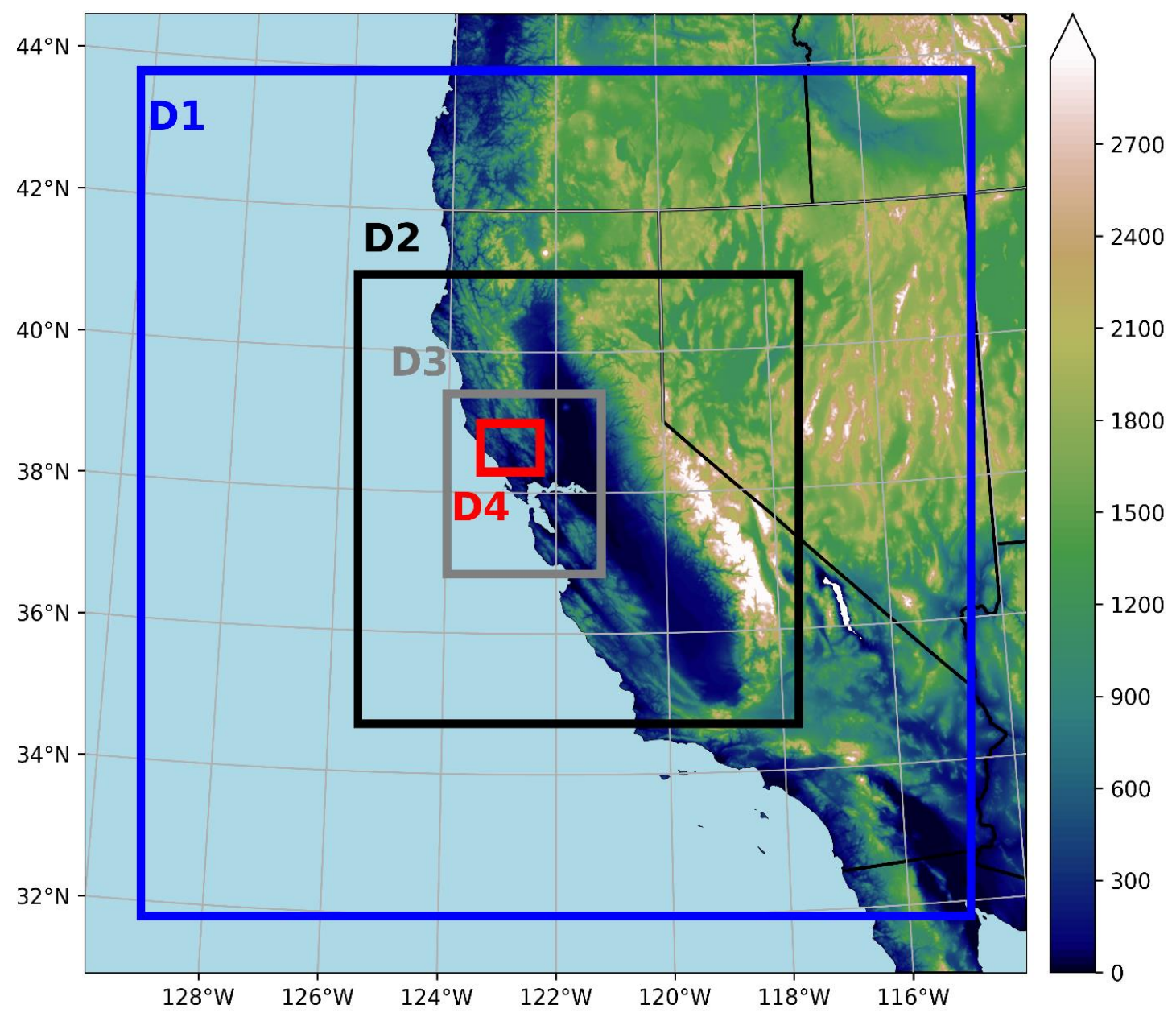

Figure 12. Domains for WRF simulation with topography shaded in meters. D1, D2, D3, and D4 have horizontal resolution of $9 \mathrm{~km}, 3 \mathrm{~km}, 1 \mathrm{~km}$, and $0.333 \mathrm{~km}$, respectively. 


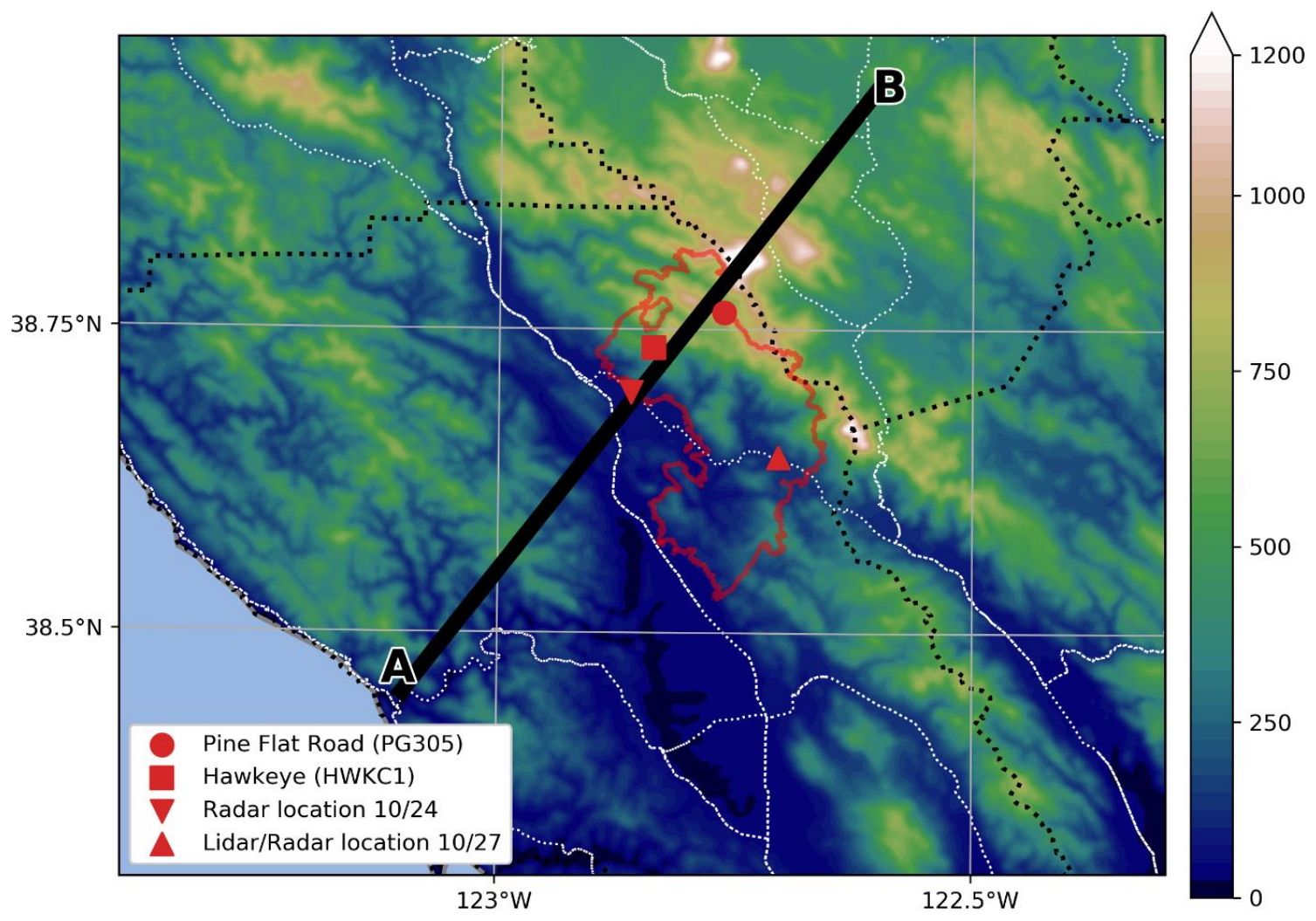

Figure 13. Domain 4 overview with a few key locations marked in red. The red outline is the final perimeter of the Kincade Fire. The black line represents the cross section. $A(B)$ is the starting (ending) point.

The model calibration was performed using surface wind observations evaluated against the $1 \mathrm{~km}$ WRF domain. Surface observations from 76 surface stations (Table 3) from multiple networks including NWS stations, RAWS stations, PG\&E stations, WWG-Sonoma, and SJSUNET were used for surface wind verification. It must be noted that the use of multiple networks adds a layer of uncertainty due to differing sampling rates and instrument mounting height. These differences were assumed negligible as it has previously been discovered that station siting is the key controller [8]. Further, site specific metadata, such as anemometer height, for the PG\&E and WWG-Sonoma networks was 
unavailable. Surface wind error statistics for the $10 \mathrm{~m}$ sustained windspeed included the root mean square error (RMSE) and bias calculations. RMSE was chosen over mean absolute error (MAE) because it was more sensitive to large errors and was therefore more useful because large errors were especially undesirable. Surface temperature and surface dewpoint were also assessed once the physics parameterizations were fine-tuned with the surface windspeed analysis.

The calibration simulation was performed for all five PSPS events. It was first calibrated with the most severe event (WE1) which was initialized at 1200 UTC 26 October 2019 and had a twelve-hour spin-up, yielding 36 hours of integrated simulation time. The simulation calibration began with conus options and explored the performance of $5 \mathrm{PBL}$ schemes. The LSM was then fine-tuned for the best PBL. The combination of parameterizations that yielded the best simulation performance (Table 4) for surface wind speed was used to expand the simulation to the four remaining PSPS events of interest. The details of each simulation are documented in Table 5. 
Table 3. List of surface weather stations used for WRF calibration. Temperature, dewpoint temperature, relative humidity, windspeed, wind direction, and gust were collected for each of these stations.

\begin{tabular}{|c|c|c|c|}
\hline ID & Station Name & Elevation (ft) & Network \\
\hline AIRWW & Mark West-North (Ranch 14) & 112 & Western Weather \\
\hline ATLC1 & Atlas Peak & 1934 & RAWS \\
\hline BNDC1 & Ben Lomond & 2598 & RAWS \\
\hline BRSWW & Fulton-SE (BARNES Rd) & 145 & Western Weather \\
\hline BOTWW & Occidental Rd (Sebastopol) & 93 & Western Weather \\
\hline BVYWW & Lower Bennet Valley & 425 & Western Weather \\
\hline DENWW & River Rd South (Denner Road) & 95 & Western Weather \\
\hline DRYWW & Lower Dry Creek Valley & 130 & Western Weather \\
\hline F11WW & Sonoma Valley (Bedrock) & 173 & Western Weather \\
\hline F40WW & Geyserville-South (Nervo Station) & 354 & Western Weather \\
\hline FOTWW & Windsor-East (Ranch 16) & 178 & Western Weather \\
\hline HOFWW & Geyserville-North (Hoffman) & 212 & Western Weather \\
\hline HPDC1 & Hopland UC & 2682 & RAWS \\
\hline HSPC1 & Spring Valley & 1075 & RAWS \\
\hline HWKC1 & Hawkeye & 2024 & RAWS \\
\hline KCCR & Concord, Buchanan Field & 23 & ASOS \\
\hline KE16 & South County Airport of Santa Clara County & 281 & ASOS \\
\hline KELC1 & Konocti & 2163 & RAWS \\
\hline KENWW & Kenwood (KUNDE) & 411 & Western Weather \\
\hline KHWD & Hayward, Hayward Air Terminal & 46 & ASOS \\
\hline KNXC1 & Knoxville Creek & 2200 & RAWS \\
\hline KOAK & Oakland, Metro Oakland International Airport & 3 & ASOS \\
\hline KSTS & Santa Rosa, Santa Rosa Sonoma County Airport & 125 & ASOS \\
\hline KWVI & Watsonville, Watsonville Municipal Airport & 161 & ASOS \\
\hline LAHC1 & La Honda & 804 & RAWS \\
\hline LOAC1 & Los Altos & 539 & RAWS \\
\hline LSGC1 & Los Gatos & 1842 & RAWS \\
\hline LSLWW & HWY 128/Chalk Hill Rd (Landslide) & 185 & Western Weather \\
\hline LTRC1 & Las Trampas & 1760 & RAWS \\
\hline LVMC1 & Mallory Ridge & 1948 & RAWS \\
\hline MDEC1 & Middle Peak & 2339 & RAWS \\
\hline MIPC1 & Poverty & 2066 & RAWS \\
\hline OKSC1 & Oakland South & 1095 & RAWS \\
\hline ONOC1 & Oakland North & 1403 & RAWS \\
\hline PEAC1 & Calaveras Road & 1230 & RAWS \\
\hline PG011 & Cull Canyon Road & 1360 & PG\&E \\
\hline PG013 & Palomares Road & 373 & PG\&E \\
\hline PG019 & Upper Soda Canyon Road & 1515 & PG\&E \\
\hline PG038 & Highway 128 Sonoma & 684 & PG\&E \\
\hline PG045 & Chiles Pope Valley Road & 867 & PG\&E \\
\hline PG060 & Seigler Springs & 2579 & PG\&E \\
\hline PG079 & Middletown NW & 1164 & PG\&E \\
\hline PG081 & Bald Mountain & 2874 & PG\&E \\
\hline PG084 & King Ridge Road & 1470 & PG\&E \\
\hline PG085 & Butts Canyon Road North & 1091 & PG\&E \\
\hline PG090 & Ridge Ranch & 1352 & PG\&E \\
\hline PG091 & White Sulphur Springs & 1059 & PG\&E \\
\hline PG110 & Noble Ranch & 1832 & PG\&E \\
\hline PG126 & Mt. St. Helena East & 4220 & PG\&E \\
\hline PG127 & Steele Canyon Road & 820 & PG\&E \\
\hline PG132 & Mt. St. Helena West & 4340 & PG\&E \\
\hline PG177 & Sonoma Mountain Road & 2390 & PG\&E \\
\hline PG201 & Schmitt \& Hwy 128 & 300 & PG\&E \\
\hline PG228 & Butts Canyon Road South & 1011 & PG\&E \\
\hline PG243 & Skaggs Springs & 981 & PG\&E \\
\hline PG244 & Ida Clayton Road & 2252 & PG\&E \\
\hline PG251 & Wall Road & 1525 & PG\&E \\
\hline PG281 & Truitt & 1751 & PG\&E \\
\hline PG284 & Highway 101 Hilltop & 990 & PG\&E \\
\hline PG303 & Healdsburg Hills North & 2480 & PG\&E \\
\hline PG305 & Pine Flat Road & 3308 & PG\&E \\
\hline PG358 & Knoxville & 1998 & PG\&E \\
\hline PG370 & Ormsey Cutoff Trail & 2513 & PG\&E \\
\hline PG515 & Pulgas Ridge & 1066 & PG\&E \\
\hline PIBC1 & Black Diamond & 1600 & RAWS \\
\hline PICWW & Jimtown_North (Piccolo-R15) & 185 & Western Weather \\
\hline PLEC1 & Briones & 1450 & RAWS \\
\hline R05WW & Fulton-NW (Ranch 5) & 113 & Western Weather \\
\hline R08WW & Windsor-NW (Ranch 8) & 123 & Western Weather \\
\hline RJSC1 & San Jose & 675 & RAWS \\
\hline RSAC1 & Santa Rosa & 599 & RAWS \\
\hline RSPC1 & Rose Peak & 3060 & RAWS \\
\hline RVOWW & Lytton (River Oaks) & 172 & Western Weather \\
\hline SJSO2 & Mt. Diablo & 37849 & SJSUNET \\
\hline SJSO4 & Umunhum South & 3225 & SJSUNET \\
\hline SPRWW & Rohnert Park-West (Stony Point) & 88 & Western Weather \\
\hline
\end{tabular}


Table 4. Summary of WRF parameterization options.

\begin{tabular}{llr} 
Parameterization & Physics Scheme & Option \\
\hline Microphysics & WSM 6-class graupel scheme & 6 \\
Radiation (LW \& SW) & RRTMG & 4 \\
Surface Layer & Revised MM5 & 1 \\
Land-surface model & Noah-MP & 4 \\
Boundary layer & Shin-Hong & 11 \\
\hline \hline
\end{tabular}

Table 5. Details are listed for each simulations' start and end times. All simulations have a twelve-hour spin-up period and the "Hours Analyzed" refers to the number of hours used to calculate error statistics which fluctuated based on the duration of the event. The network averaged RMSE and Bias for surface wind speed of each simulation is listed.

\begin{tabular}{|c|c|c|c|c|c|}
\hline & WE1 & WE2 & WE3 & WE4 & WE5 \\
\hline Start & $120026-O c t$ & 0600 9-Oct & 0000 23-Oct & 1800 28-Oct & 1200 5-Oct \\
\hline End & 1800 28-Oct & $120011-O c t$ & $060025-O c t$ & 0000 31-Oct & 0600 7-Oct \\
\hline Hours Analyzed & 36 & 42 & 36 & 36 & 24 \\
\hline RMSE & 3.63 & 2.47 & 2.52 & 2.26 & 1.61 \\
\hline Bias & 0.49 & -0.1 & -0.01 & -0.13 & -0.18 \\
\hline
\end{tabular}

A "gray zone" simulation with no PBL scheme in Domain 4 was also performed to assess the simulation's capability to explicitly resolve the boundary layer turbulence [39]. Turbulence closure was attained by employing a turbulent kinetic energy (TKE) 1.5-order closure. A decreased timestep from 36 seconds to 27 seconds, in Domain 1, was necessary to achieve numerical stability when no PBL scheme was used.

\subsection{Model Performance}

\section{a. Model Configuration}

After multiple PBL schemes were tested, the Shin-Hong scale aware yielded the best simulation performance with respect to surface windspeed. It was then further refined with the final Namelist options (Table 4) resembling the 
configuration used by [39] except for the LSM, and this optimized configuration yielded an event and network averaged RMSE (Bias) of 3.63 (0.49) for WE1. The Noah LSM was used by Xue and was "improved" by [43]. The "improvement" was with respect to the roughness length used by the Noah LSM which were increased to match those used by the Pleim-Xiu LSM. This process was replicated in this study using the WE3 simulation. The Shin-Hong PBL was utilized with the Noah LSM. The VEGPARM.TBL was then edited to replicate the adjustment of roughness lengths documented by [43] and the simulation was performed again. This brought improvements to the RMSE from 3.14 to 2.75 and bias from 1.04 to 0.35 . However, the Noah-MP LSM paired with the Shin-Hong PBL yielded the smallest RMSE of 2.52 and bias of -0.01 .

\section{b. Surface Network Performance}

The performance of each surface network was analyzed with the calibrated simulation for WE1 to diagnose their individual impacts on the error statistic calculations. The model performed reasonably well with the all network average. In general, WRF overestimated lower windspeed observations and underestimated higher windspeed observations (Figure 14a). Some interesting observations were made when each network was analyzed separately. First, was that the ASOS network had the best performance. This is likely due to the inclusion of the ASOS network in the data assimilation process of NAM. Secondly, the PG\&E network had the least desirable performance. That is that many strong wind observations were severely underpredicted by WRF. This 
could be due to a multitude of things including some stations which are mounted at powerline height (well above the $10 \mathrm{~m}$ assumption). Also, PG\&E has done a good job at expanding their network with a focus on remote areas that are highly exposed to offshore flow events. Third, it was anticipated that WRF would overpredict the RAWS network because the RAWS anemometer mounting height is at $6.1 \mathrm{~m}$ and was directly compared to WRF's $10 \mathrm{~m}$ windspeed. However, WRF tends to have more underestimation of strong wind speeds observed by RAWS. Lastly, the western weather group network has a station citing issue which it acknowledged by WRF's ubiquitous overestimation of the observed surface winds. 

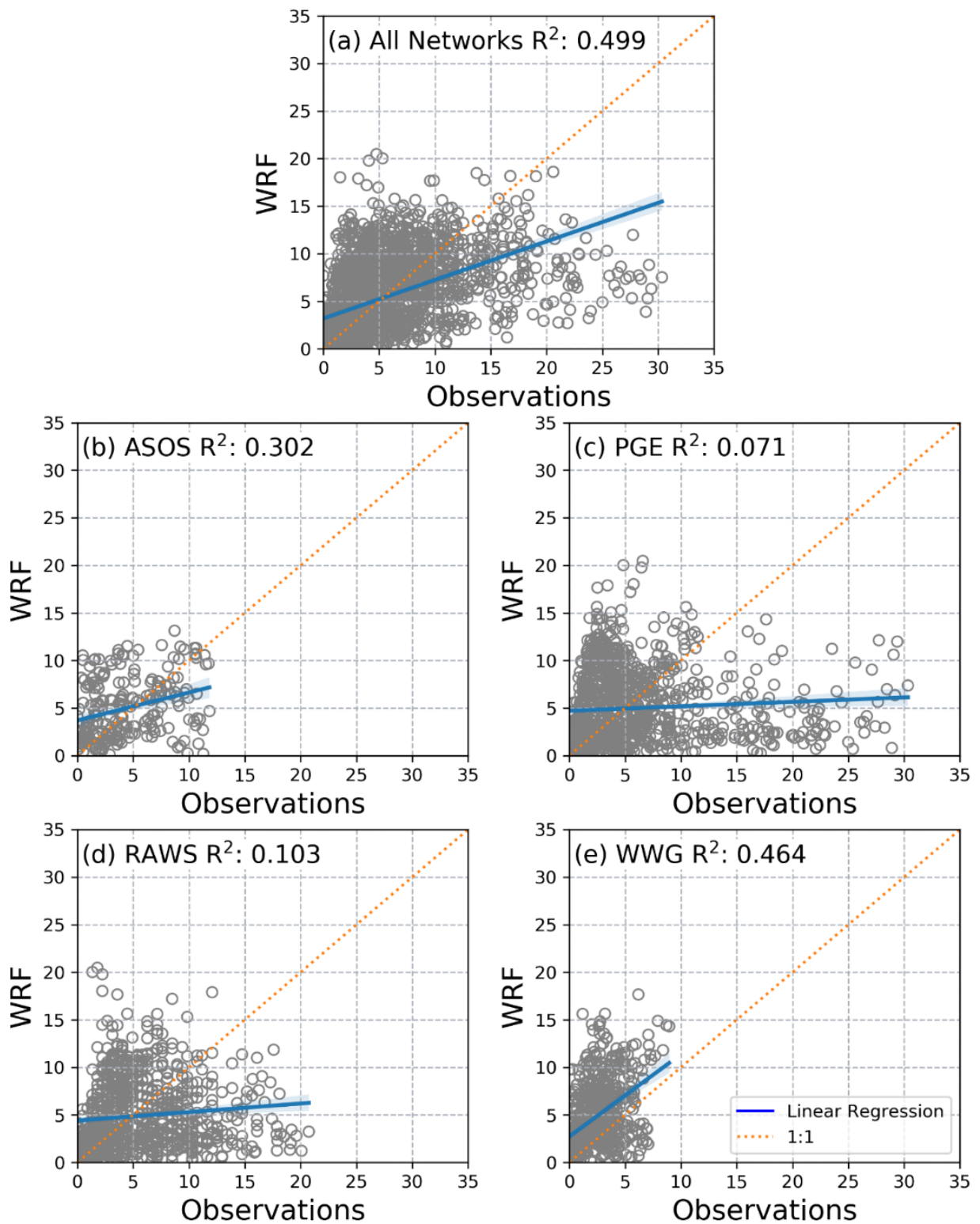

Figure 14. WRF's surface wind speed $\left(\mathrm{m} \mathrm{s}^{-1}\right)$ forecast performance for all networks (a), the ASOS network (b), the PG\&E network (c), the RAWS network (d), and the western weather group network (e). The gray hollow circles represent each data point, the blue line is a fitted linear regression with its $95 \%$ confidence (light blue shading), and the dotted orange line is the 1:1 line (perfect forecast). Each panel also has its associated $\mathrm{R}^{2}$ value shown 


\section{c. Horizontal Resolution Optimization}

A secondary calibration analysis diagnosed the best horizontal resolution. This was done by turning nested feedback off and calculate the same surface wind speed error statistics as previously mentioned. However, many of the sites used for verification of the $1 \mathrm{~km}$ domain were not within the $1 / 3 \mathrm{~km}$ domain. There were 46 surface stations used that were within the bounds of domain 4 . These stations were used to calculate the error statistics in this region for the 3 , 1 , and $1 / 3 \mathrm{~km}$ domains without nested feedback. This was performed using surface windspeed and surface temperature for WE1, WE2, and WE3. In all three cases, the 1 and $3 \mathrm{~km}$ domain performed better than the $1 / 3 \mathrm{~km}$ domain for

surface wind speed. In contrast, the temperature was forecasted best by the $1 / 3$ $\mathrm{km}$ domain for all three cases. It is speculated that This implies that subkilometer horizontal resolution is not beneficial for forecasting surface windspeed, but it is however beneficial for forecasting surface temperature.

\section{d. Gray Zone Exploration}

A Gray Zone simulation was performed by turning off the PBL. A similar approach to Xue was used where subgrid-scale turbulence was closed with a TKE 1.5-order closure [39]. Preliminary results observed potential for better simulation performance of the high elevation sites that were most exposed. Wind intensity at these sites was severely underestimated with all PBL options explored. However, the gray zone simulation severely overestimated the surface winds everywhere and was appraised to be nonbeneficial. The outline of Domain 
4, which was not using a PBL scheme, was discernable in Domain 3's surface wind speed by a stark increase in intensity inside the domain (not shown). Further, this overestimation spread into the parent domains, primarily downstream of Domain 4.

\subsection{Mountain Wave Analysis}

\section{a. Wind Event 1 (WE1)}

The strongest event analyzed was WE1 with a gust measured in excess of $44.7 \mathrm{~m} \mathrm{~s}^{-1}(100 \mathrm{mph})$. Very dry N-NE winds were observed at all elevations of the leeward slopes of all three regions. The mechanisms responsible for such widespread impacts are observed in a cross section through the Wine Country region (Figure13). First is the strong low-level temperature inversion $\sim 3^{\circ} \mathrm{C}$ upstream of the ridgeline (Figure 15a). Below this inversion, a shallow jump-like feature developed (Figure 16a). This transitioned to high amplitude lee wave activity which was confined to the low levels. This low-level confinement of the lee waves was attributed to stability associated with the strong inversion [44] (Figure 15b). Below the high amplitude lee waves were surface winds in excess of $18 \mathrm{~m} \mathrm{~s}^{-1}$ in the vicinity of Hawkeye RAWS (Figure 16b). Also noteworthy is the significant upper level support with winds in excess of $30 \mathrm{~m} \mathrm{~s}^{-1}$. As the event evolved, the lee waves detached from the surface and the flow became blocked in the lee of the ridge (Figure 16c). This was only a lull in the event before the strong winds again surfaced (Figure 16d). 

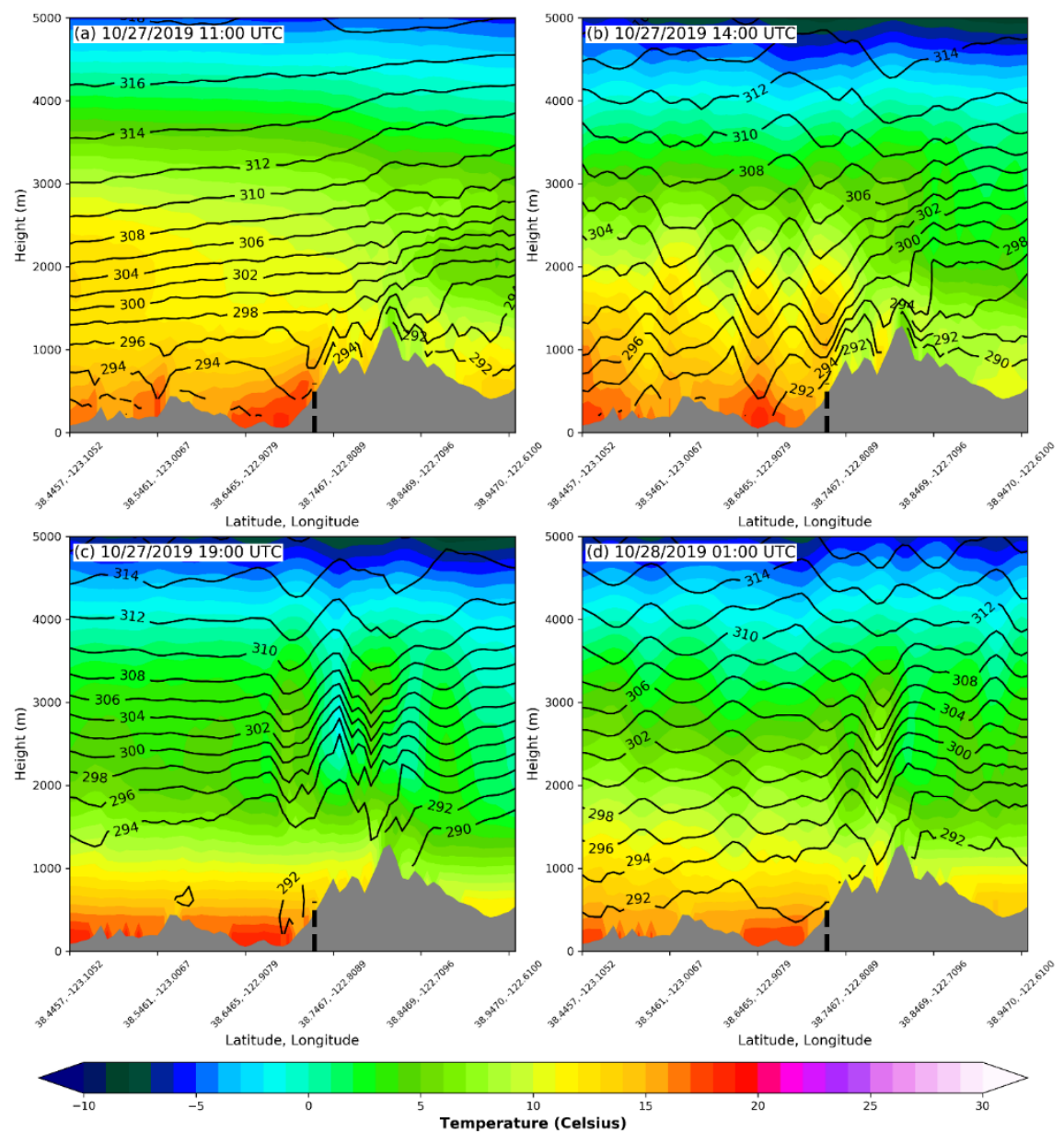

Figure 15. Cross section of temperature from figure 13 during WE1 simulation with theta contours (Kelvin) and temperature (Celsius) shaded. The black vertical dashes in the terrain represent the approximate location of Hawkeye (HWKC1) RAWS. 


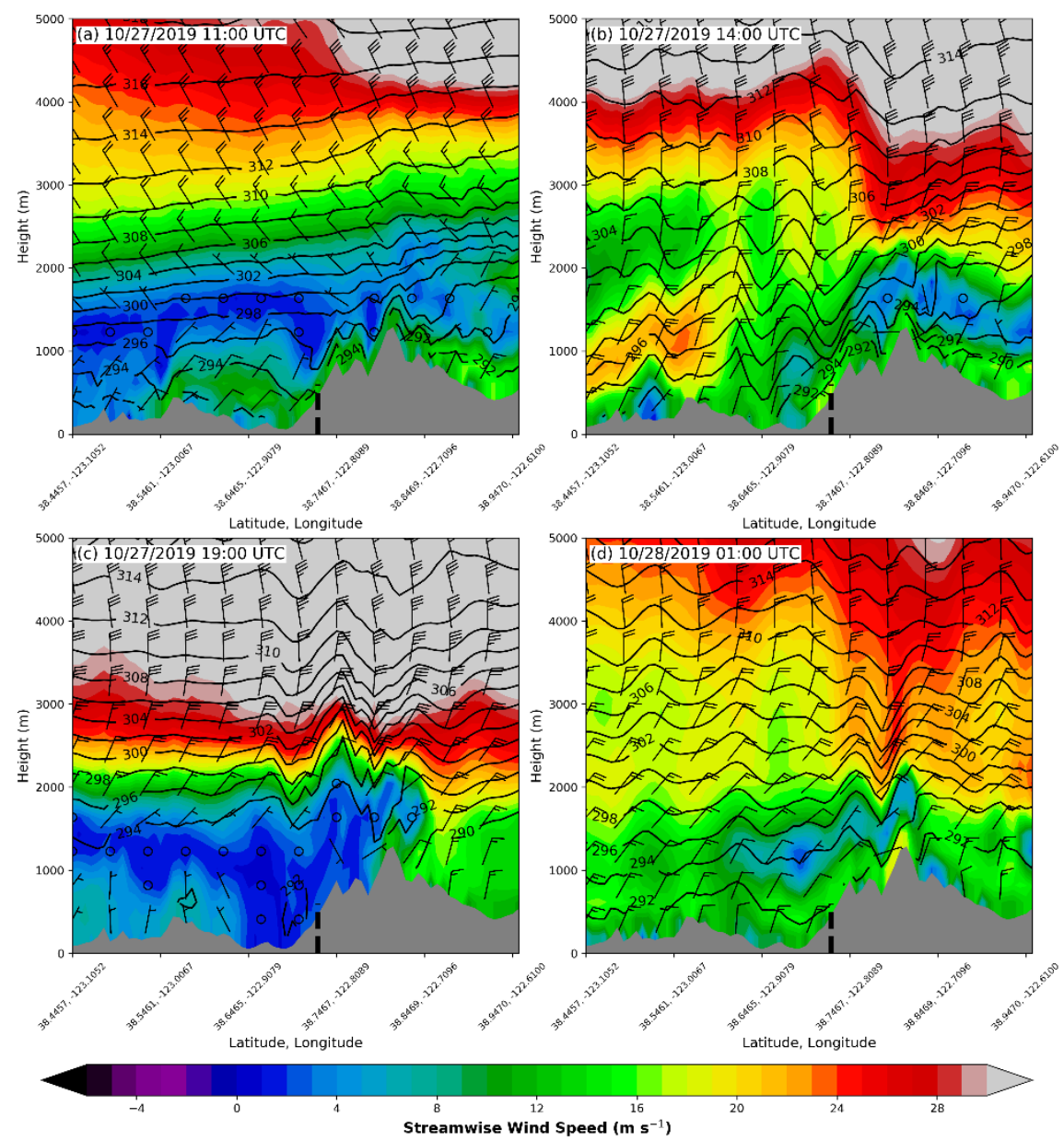

Figure 16. Cross section of streamwise windspeed from Figure 13 during WE1 simulation with theta contours in Kelvin and streamwise wind speed $\left(\mathrm{m} \mathrm{s}^{-1}\right)$ shaded. The black vertical dashes in the terrain represent the approximate location of Hawkeye (HWKC1) RAWS.

\section{b. Wind Event 2 (WE2)}

Wind observations at the high elevation sites verified WE2 as the second strongest event with sustained winds exceeding $30 \mathrm{~m} \mathrm{~s}^{-1}$ in the Wine Country region. The lower elevations observed discrepantly lower wind speeds, particularly in the Wine Country region. This was attributed to a significant decrease of lower tropospheric mountain wave activity which was likely due to the absence of a temperature inversion above crest height (Figure 17). A 
shallow jump-like feature developed with small amplitude lee waves above (Figure 17a). However, this jump-like feature was short lived and did not exhibit the typical offshoot of strong winds as expected from a hydraulic jump [31] (Figure 18a). The small amplitude lee waves persisted for some time before transitioning to weak vertically propagating mountain wave activity near the end of the event (Figure 17d). The lack of upper level support was evident with this event which observed a maximum of $\sim 15 \mathrm{~m} \mathrm{~s}^{-1}$ below $3000 \mathrm{~m} \mathrm{AGL} \mathrm{(Figure} \mathrm{18).}$ An area of strong winds had surfaced upstream of the ridge but a blocking feature on the leeward side interjected these strong surface winds (Figure 18c). 

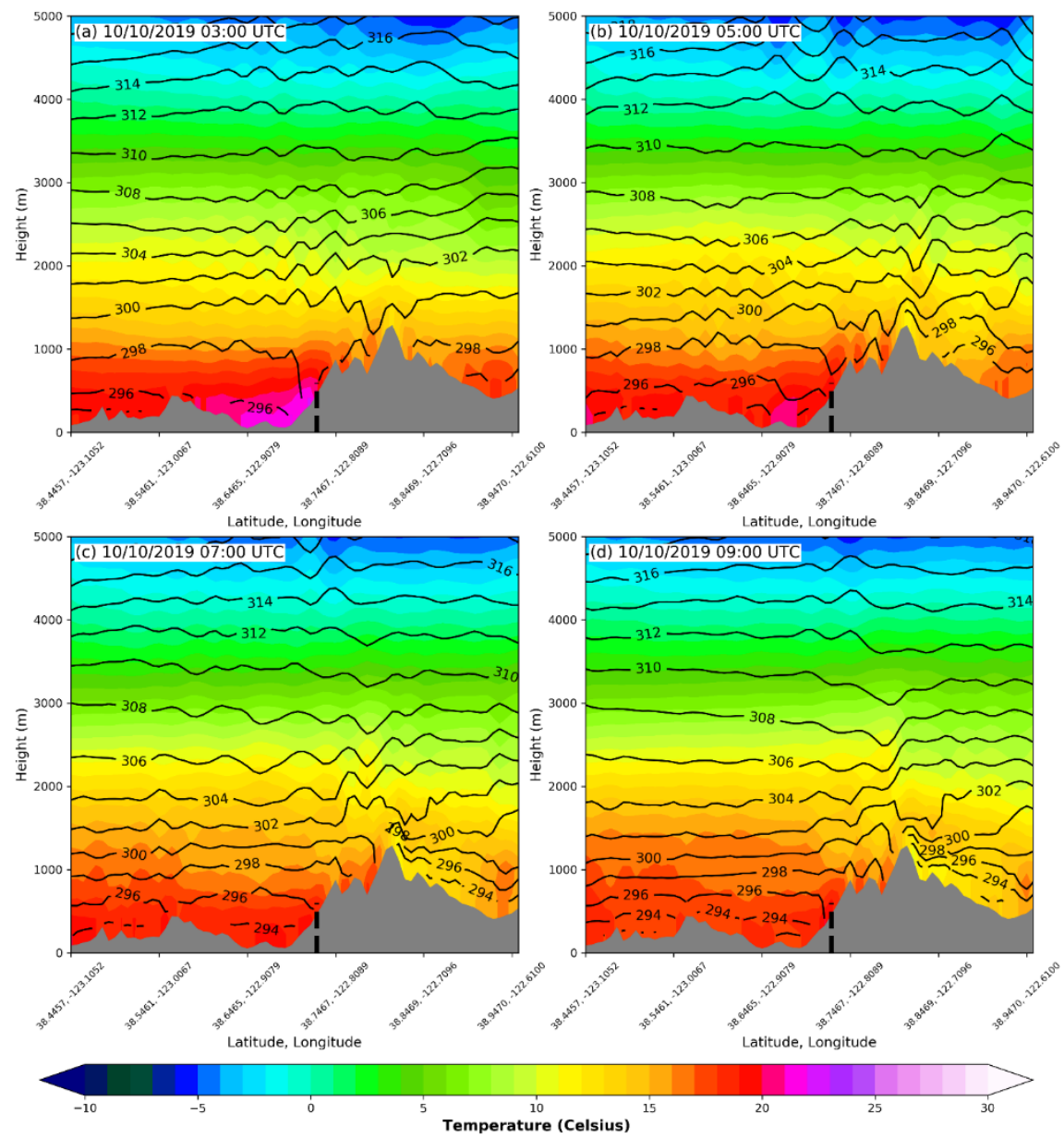

Figure 17. Same as Figure 15, but for WE2. 


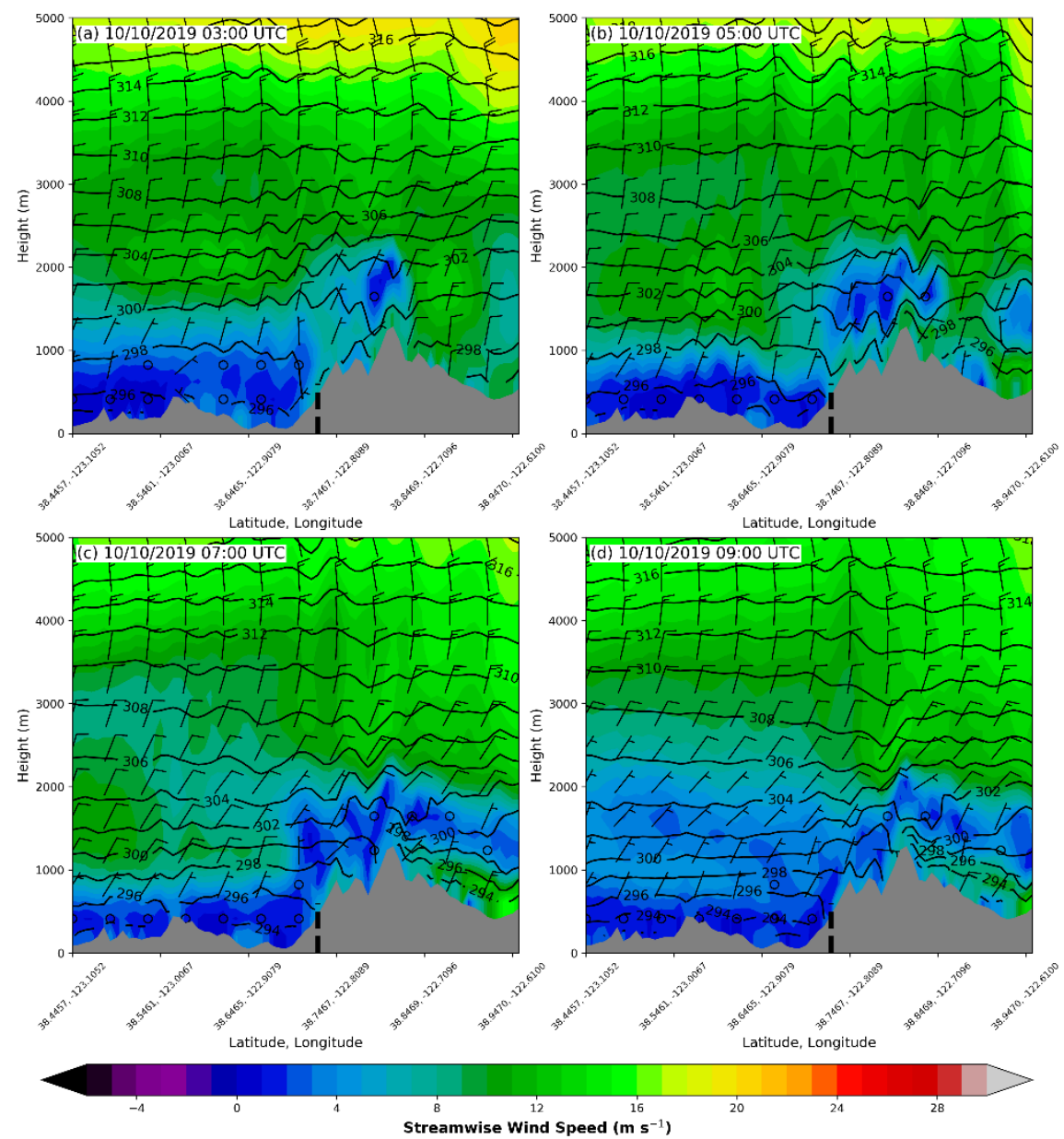

Figure 18. Same as Figure 16, but for WE2.

c. Wind Event 3 (WE3)

Less intense winds were observed in the high elevations during WE3 as compared to WE2. However, the mid to lower elevations observed stronger winds than WE2, particularly in the Wine Country region. This inconsistency was a result of increased mountain wave activity during WE3. The event began with a vertically propagating mountain wave (Figure 19a), before wave energy was deflected towards the surface (Figure 19b). A distinct temperature inversion upstream of the ridge, as was observed in WE1, was absent. However, a very 
weak vertical temperature gradient was observed upstream of the ridge between 2000-3000 m AGL (Figure 19b). This weak temperature gradient in the vertical indicated a layer of stability which is believed to have aided in the downward deflection of energy [44]. While this downward wave deflection did not directly impact the surface winds, it allowed isentropic drawdown of drier air aloft (not shown). A critical layer was observed below the primary mountain wave (Figure 20c) and below that critical layer was a stream of strong surface winds. These strong winds were associated with a jump-like feature (Figure 20c,d) which observed the typical offshoot of strong winds and was contrary to what WE2 observed. Finally, this event had less upper level support than WE2. 

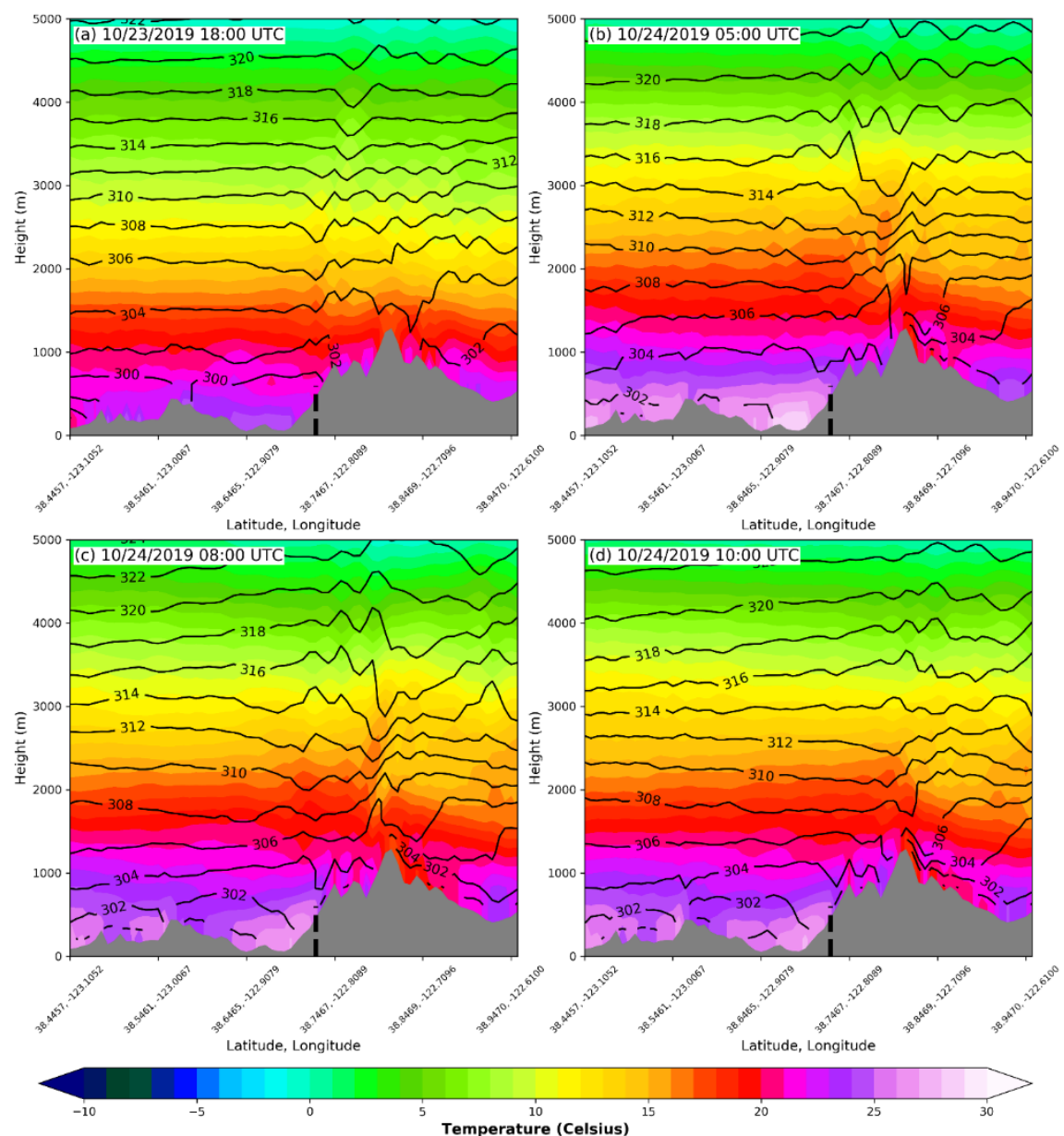

Figure 19. Same as Figure 15, but for WE3. 


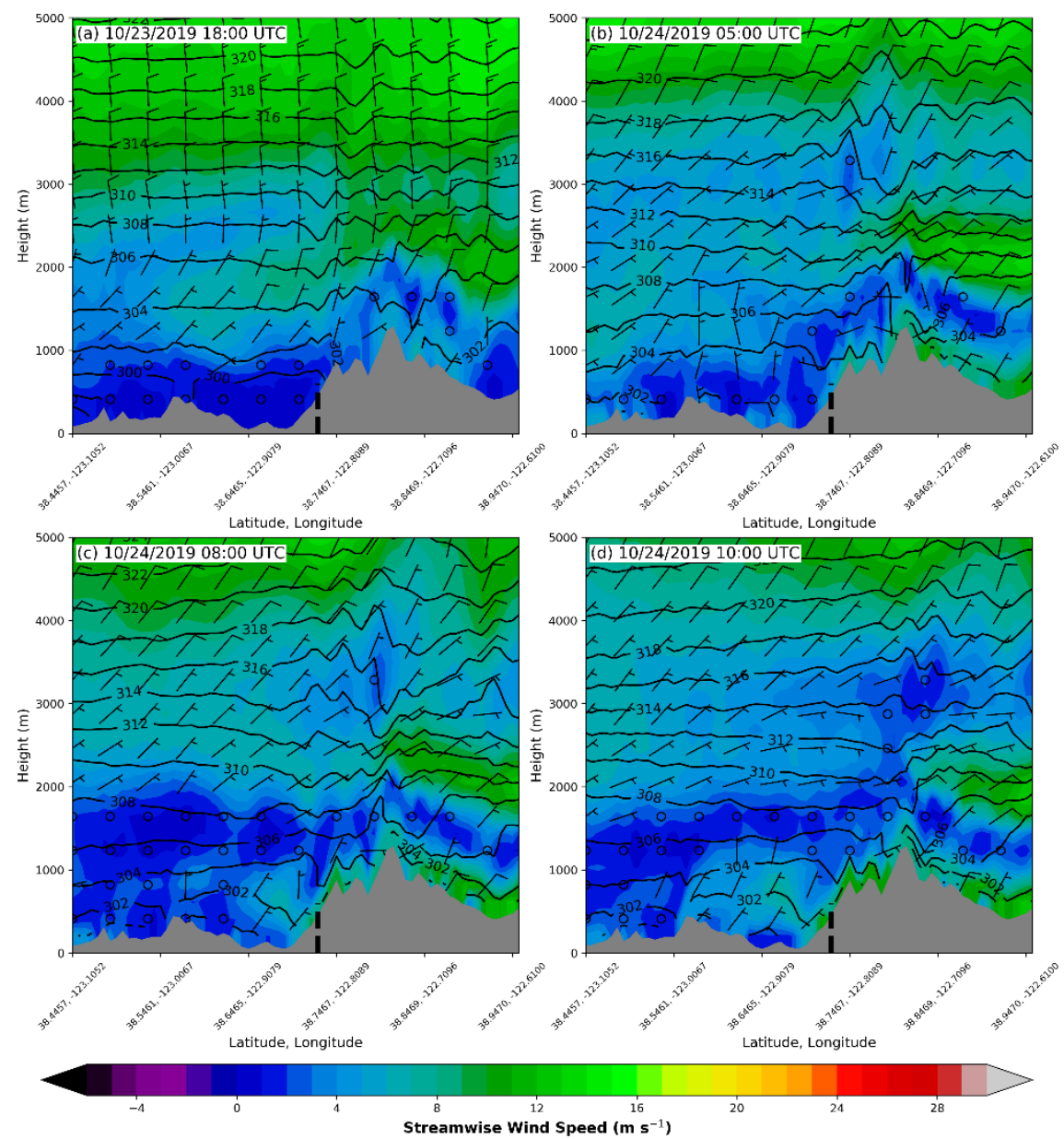

Figure 20. Same as Figure 16, but for WE3.

\section{d. Wind Event 4 (WE4)}

As anticipated from our pressure gradient intensity categorization, WE4 was less intense than the previously analyzed events. A temperature inversion was clearly identifiable (Figure 21c) unlike WE2 and WE3. Upper level support was also evident (Figure 22a), but strong surface winds were lacking. Minimal mountain wave activity occurred during WE4 which was attributable to the surface winds lacking significant intensity. These conditions all lead to moderate wind strength isolated to the higher elevations (Figure 22c,d). 

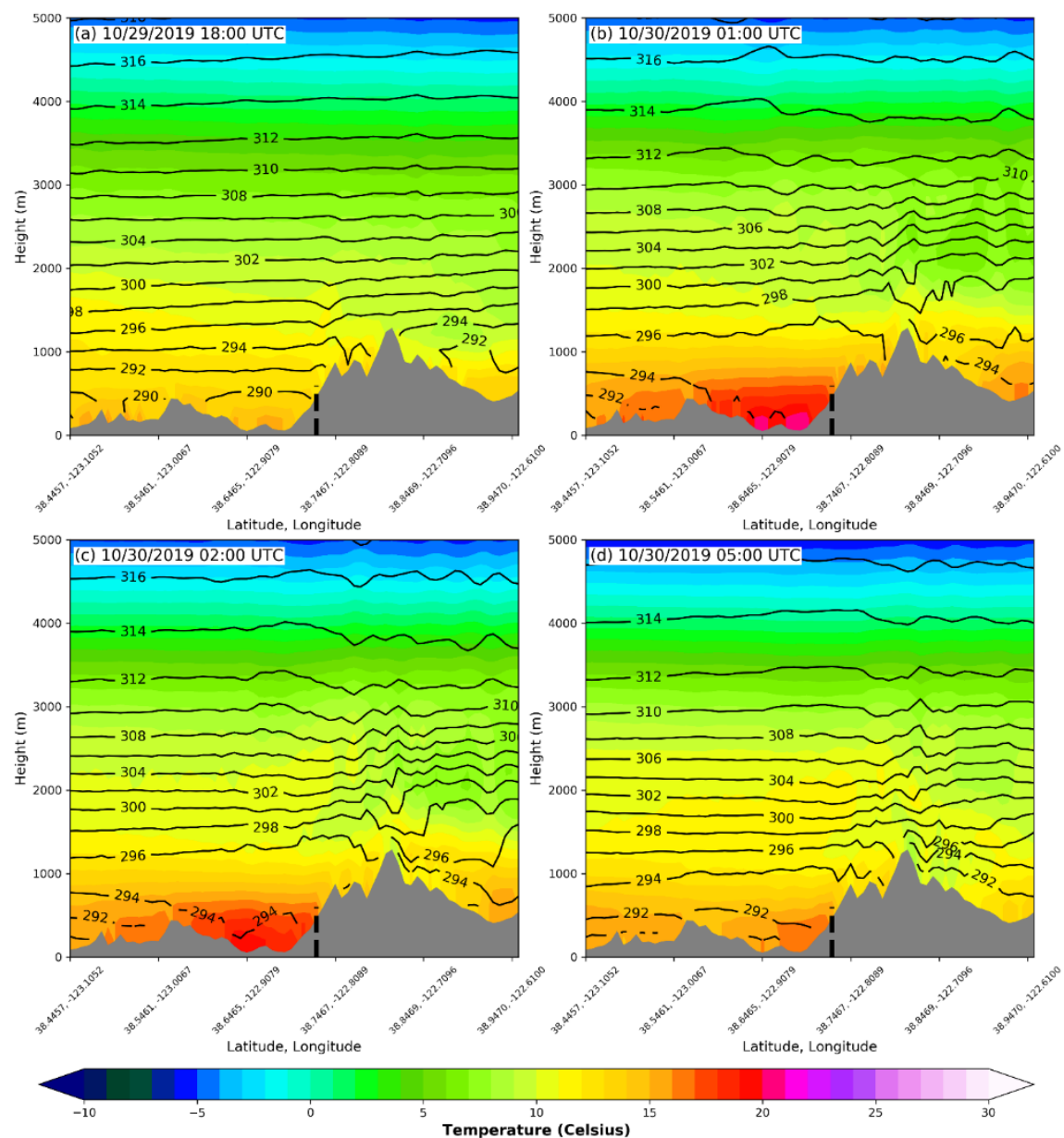

Figure 21. Same as Figure 15, but for WE4. 


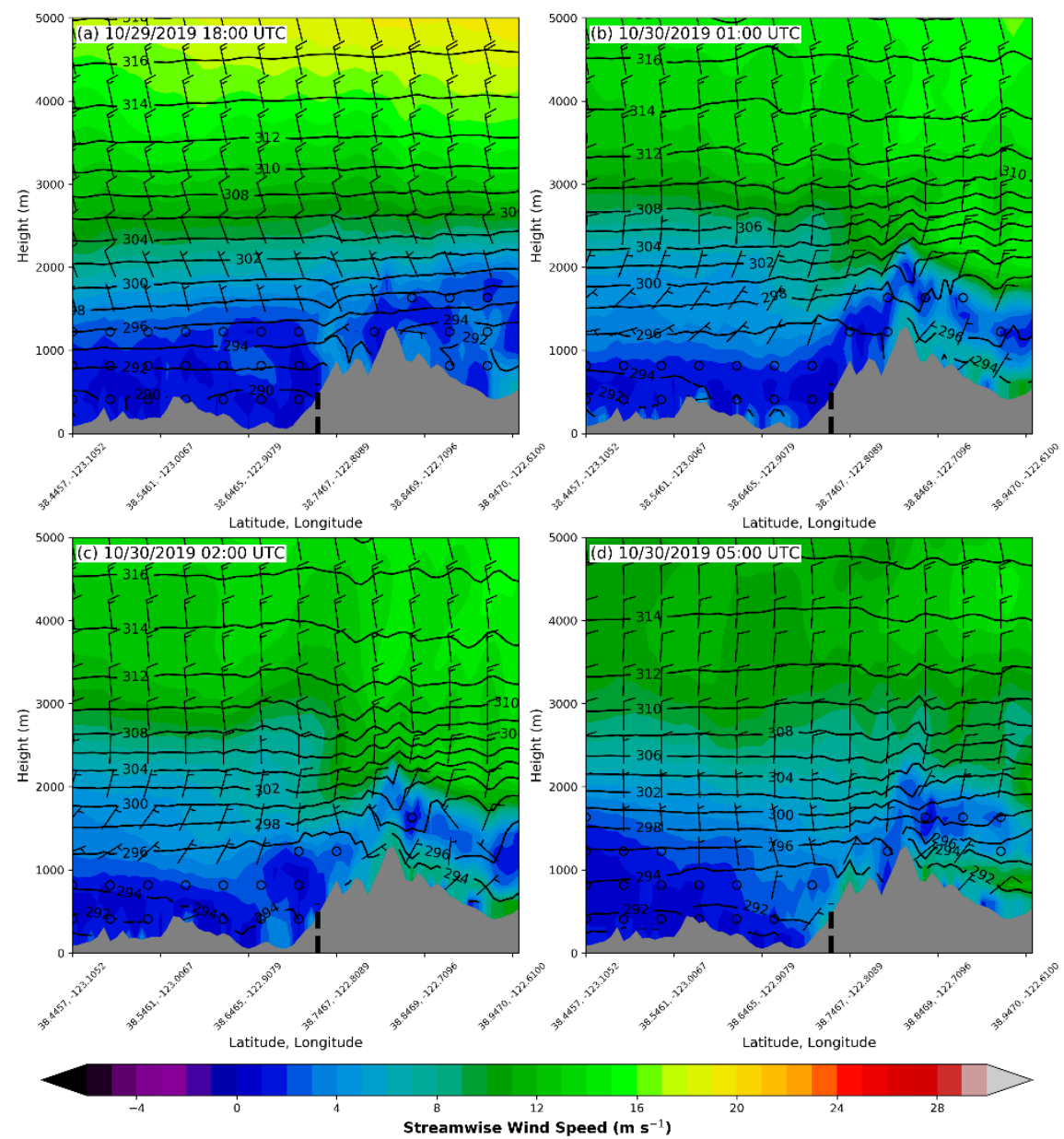

Figure 22. Same as Figure 16, but for WE4.

\subsection{Discussion and Summary}

It has been shown that after calibration, WRF has considerable skill simulating surface wind speeds during downslope windstorms. Our simulation achieved a minimum RMSE (Bias) of $3.63(0.49)$ during the most severe event (WE1). Owing to this result was the performance of each surface network that was used to access simulation skill. WRF had the most difficulty when it came to simulating winds observed by the PG\&E surface network. It is speculated that this may stem from the absence of these stations in the data assimilation process 
for the NAM which was used to drive this simulations initial and lateral boundary conditions. The lack of station metadata to confirm instrument height added uncertainty, but site exposure was also observed to contribute to WRF's underestimations. That is that PG\&E had many ridgeline sites that were totally exposed to the NE Diablo Winds. Further, we demonstrated that $1 \mathrm{~km}$ was the optimal horizontal resolution for surface wind speed of our simulation. Surface wind speed RMSE increased in our sub kilometer domain for simulations of WE1, WE2 and WE3 which indicated a decrease in simulation accuracy. However, the sub kilometer domain increased simulation accuracy for surface temperature in simulations of WE1, WE2, and WE3. The failure to upgrade the land use data, as was done with the terrain data, may have contributed to the decrease forecast skill of surface wind speed through misrepresentation of roughness lengths.

Finally, wave dynamics were analyzed and compared between events. It was determined that the absence of a temperature inversion at or above crest height during WE2 resulted in decreased mountain wave activity. This decease in mountain wave activity was associated with moderate to weak winds observed on the lee slopes.

\subsection{Conclusions}

It has been confirmed that PG\&E only initiated PSPSs when weather conditions were conducive for rapid fire spread. All PSPS events analyzed occurred during periods of offshore flow which are often associated with downslope windstorms and extreme fire weather conditions. However, one of 
the events (WE5) was classified as a borderline event that had more forecast uncertainty. The uncertainty was owed to the presence of ingredients necessary for downslope windstorms, but ultimately the event lacked upper level support and subsequently lacked sufficiently strong surface winds. We believe that an operational network of vertical profilers would assist in the mitigation of this forecast uncertainty. With such a network, critical details of the vertical atmospheric structure would be frequently observed by forecasters and this data may also be used to assimilate forecast models. Observations analyzed herein, also exposed the dynamic nature of downslope windstorms. This dynamic nature was observed during WE2 with strong winds near the ridgeline and a sharp intensity decrease in the lee of the ridgeline. WRF simulations confirmed that this observation was attributed to decreased mountain wave activity. The simulations of WRF also affirmed its utility, but the optimal configuration is of utmost importance. It was recognized that POMMS has additional utility with its 30-year climatology giving it the ability to use analog forecast techniques. However, POMMS is a $3 \mathrm{~km}$ simulation and our study produced slightly better simulation accuracy with $1 \mathrm{~km}$ horizontal resolution. Wildfire vulnerability is extremely prevalent in California and consequently public safety power shutoffs are inevitably a new reality. 


\section{References}

1. Top 20 Most Destructive California Wildfires Available online: https://www.fire.ca.gov/media/11417/top20_destruction.pdf (accessed on Apr 4, 2020).

2. Cal Fire News Release Available online:

https://www.fire.ca.gov/media/5121/campfire_cause.pdf (accessed on Oct $17,2020)$.

3. Public Safety Power Shutoff FAQ Available online:

https://www.pge.com/en_US/safety/emergency-preparedness/naturaldisaster/wildfires/public-safety-power-shutoff-faq.page). (accessed on Apr 17, 2020).

4. 2019 Utility Company PSPS Post Event Reports Available online: https://www.cpuc.ca.gov/general.aspx?id=6442466222 (accessed on Oct $20,2020)$.

5. CPUC To Examine Recent Utility PSPS Events and Consider Enforcement Actions Available online: https://docs.cpuc.ca.gov/PublishedDocs/Published/G000/M319/K766/3197 66482.PDF (accessed on May 10, 2020).

6. Huang, C.; Lin, Y.L.; Kaplan, M.L.; Charney, J.J. Synoptic-scale and mesoscale environments conducive to forest fires during the October 2003 extreme fire event in Southern California. Journal of Applied Meteorology and Climatology 2009, 48, 553-579, doi:10.1175/2008JAMC1818.1.

7. Brewer, M.J.; Clements, C.B. The 2018 Camp Fire: Meteorological Analysis Using In Situ Observations and Numerical Simulations. Atmosphere 2019, 11, 47, doi:10.3390/atmos11010047.

8. Fovell, R.; Gallagher, A. Winds and Gusts during the Thomas Fire. Fire 2018, 1, 47, doi:10.3390/fire1030047.

9. Bowers, C.L. The Diablo Winds of Northern California. Master's Thesis, San Jose State University, San Jose, CA, USA, 2018.

10. Brinkmann, W.A.R. What is A foehn? Weather 1971, 26, 230-240, doi:https://doi.org/10.1002/j.1477-8696.1971.tb04200.x.

11. Whiteman, C.D. Mountain Meteorology, Fundamentals and Applications; Oxford University Press, 2000; 
12. Durran, D.R. Mountain Waves and Downslope Winds. Atmospheric Processes Over Complex Terrain 1990, 23, 59-81.

13. Rothermel, R.C. A Mathematical Model for Predicting Fire Spread in Wildland Fuels; Ogden, Utah, USA, 1972;

14. Dennison, P.E.; Moritz, M.A. Critical live fuel moisture in chaparral ecosystems: A threshold for fire activity and its relationship to antecedent precipitation. International Journal of Wildland Fire 2009, 18, 1021-1027, doi:10.1071/WF08055.

15. Cohen, J.E.; Deeming, J.D. The National Fire-Danger Rating System: basic equations. Gen. Tech. Report 1985, 16.

16. Countryman, C.M.; Philpot, C.W. Physical Characteristics of Chamise as a Wildland Fuel; 1970;

17. Countryman, C.M.; Dean, W.A. Measuring Moisture Content in Living Chaparral: a field user's manual; 1979;

18. Bradshaw, L.S.; Deeming, J.E.; Burgan, R.E.; Cohen, J.D. The 1978 National Fire-Danger Rating System: Technical Documentation; Intermountain Forest and Range Experiment Station, Ogden, UT, USA, 1983;

19. Pro-Active De-Energization Post Event Reports Available online: https://www.pge.com/en_US/residential/outages/public-safety-powershuttoff/psps-reports.page (accessed on May 5, 2020).

20. Advance Hydrological Prediction Service Available online: https://water.weather.gov/precip/download.php (accessed on Jul 14, 2020).

21. Horel, J.; Splitt, M.; Dunn, L.; Pechmann, J.; White, B.; Ciliberti, C.; Lazarus, S.; Slemmer, J.; Zaff, D.; Burks, J. MesoWest: Cooperative mesonets in the western United States. Bulletin of the American Meteorological Society 2002, 83, 211-225, doi:10.1175/15200477(2002)083<0211:MCMITW>2.3.CO;2.

22. University of Wyoming Atmospheric Sounding Available online: http://weather.uwyo.edu/upperair/sounding.html (accessed on Jan 7, 2020).

23. Clements, C.B.; Oliphant, A.J. The California State University mobile atmospheric profiling system: A facility for research and education in boundary layer meteorology. Bulletin of the American Meteorological Society 2014, 95, 1713-1724, doi:10.1175/BAMS-D-13-00179.1. 
24. Clements, C.B.; Lareau, N.P.; Kingsmill, D.E.; Bowers, C.L.; Camacho, C.P.; Bagley, R.; Davis, B. Observations from the Fire Zone the RAPID deployments to wildfires experiment (RaDFIRE). Bulletin of the American Meteorological Society 2018, 99, 2539-2559, doi:10.1175/BAMS-D-170230.1 .

25. Fire \& Weather Data Available online: https://fam.nwcg.gov/famweb/weatherfirecd/state_data.htm (accessed on Aug 21, 2020).

26. Emery, N.C.; D'Antonio, C.M.; Still, C.J. Fog and live fuel moisture in coastal California shrublands. Ecosphere 2018, 9, doi:10.1002/ecs2.2167.

27. Dettinger, M.D.; Ralph, F.M.; Das, T.; Neiman, P.J.; Cayan, D.R. Atmospheric Rivers, Floods and the Water Resources of California. Water 2011, 3, 445-478, doi:10.3390/w3020445.

28. Cao, Y.; Fovell, R.G. Downslope windstorms of San Diego County. Part I: A case study. Monthly Weather Review 2016, 144, 529-552, doi:10.1175/MWR-D-15-0147.1.

29. Jiang, Q.; Doyle, J.D. Diurnal Variation of Downslope Winds in Owens Valley during the Sierra Rotor Experiment. Monthly Weather Review 2008, 136, 3760-3780, doi:10.1175/2008MWR2469.1.

30. Werth, P.A.; Potter, B.E.; Clements, C.B.; Finney, M.A.; Goodrick, S.L.; Alexander, M.E.; Cruz, M.G.; Forthofer, J.A.; Mcallister, S.S. Synthesis of knowledge of extreme fire behavior: Volume I for fire managers. USDA Forest Service - General Technical Report PNW-GTR 2011, I, 144, doi:10.2737/PNW-GTR-854.

31. Vosper, S.B. Inversion effects on mountain lee waves. Quarterly Journal of the Royal Meteorological Society 2004, 130, 1723-1748, doi:10.1256/qj.03.63.

32. Durran, D.R. Another look at downslope windstorms. Part I: the development of analogs to supercritical flow in infinitely deep, continuously stratified fluid. Journal of the Atmospheric Sciences 1986, 43, 2527-2543, doi:10.1175/1520-0469(1986)043<2527:ALADWP>2.0.CO;2.

33. 2019 Kincade Fire After Action Report Available online: https://sonomacounty.ca.gov/DEM/pdf/2019-Kincade-Fire-After-ActionReport-March-2020/ (accessed on Oct 9, 2020).

34. NWCG Standards for Fire Weather Stations. National Wildfire Coordinating Group PMS 426-3 2019. 
35. Rolinski, T.; Capps, S.B.; Fovell, R.G.; Cao, Y.; D'Agostino, B.J.; Vanderburg, S. The Santa Ana wildfire threat index: Methodology and operational implementation. Weather and Forecasting 2016, 31, 18811897, doi:10.1175/WAF-D-15-0141.1.

36. Pacific Gas and Electric Company 2020 Wildfire Mitigation Plan Report Available online:

https://www.pge.com/pge_global/common/pdfs/safety/emergencypreparedness/natural-disaster/wildfires/wildfire-mitigation-plan/2020Wildfire-Safety-Plan.pdf (accessed on Sep 28, 2020).

37. NOAA Gridded Forecast Meteorological Data Available online: https://www.ready.noaa.gov/READYmetdata.php (accessed on May 7 , 2020).

38. Cannon, F.; Carvalho, L.M.V.; Jones, C.; Hall, T.; Gomberg, D.; Dumas, J.; Jackson, M. WRF simulation of downslope wind events in coastal Santa Barbara County. Atmospheric Research 2017, 191, 57-73, doi:10.1016/j.atmosres.2017.03.010.

39. Xue, H.; Li, J.; Qian, T.; Gu, H. A 100-m-Scale Modeling Study of a Gale Event on the Lee Side of a Long Narrow Mountain. Journal of Applied Meteorology and Climatology 2020, 59, 23-45, doi:10.1175/jamc-d-190066.1 .

40. Farr, T.G.; Rosen, P.A.; Caro, E.; Crippen, R.; Duren, R.; Hensley, S.; Kobrick, M.; Paller, M.; Rodriguez, E.; Roth, L.; et al. The shuttle radar topography mission. Reviews of Geophysics 2007, 45, doi:https://doi.org/10.1029/2005RG000183.

41. Beezley, J.D.; Kochanski, A.K.; Mandel, J. Integrating high-resolution static data into WRF for real fire simulations *. Ninth Symposium on Fire and Forest Meteorology 2011.

42. Meyer, D.; Riechert, M. Open source QGIS toolkit for the Advanced Research WRF modelling system. Environmental Modelling and Software 2019, 112, 166-178, doi:10.1016/j.envsoft.2018.10.018.

43. Cao, Y.; Fovell, R.G. Downslope windstorms of San Diego County. Part II: Physics ensemble analyses and gust forecasting. Weather and Forecasting 2018, 33, 539-559, doi:10.1175/WAF-D-17-0177.1.

44. Crook, A.N. Trapping of Low-Level Internal Gravity Waves. Journal of Atmospheric Sciences 1988, 45, 1533-1541, doi:https://doi.org/10.1175/1520-0469(1988)045<1533:TOLLIG>2.0.CO;2. 